\title{
Effect of exosomal miRNA on cancer biology and clinical applications
}

\author{
Zhenqiang Sun ${ }^{1 *}$ D, Ke Shi ${ }^{2+}$, Shuaixi Yang ${ }^{1}$, Jinbo Liu', Quanbo Zhou', Guixian Wang ${ }^{1}$, Junmin Song ${ }^{1}$, Zhen Li', \\ Zhiyong Zhang ${ }^{1}$ and Weitang Yuan ${ }^{1 *}$
}

\begin{abstract}
Exosomes, extracellular vesicles with diameters ranging from 30 to $150 \mathrm{~nm}$, are widely present in various body fluids. Recently, microRNAs (miRNAs) have been identified in exosomes, the biogenesis, release, and uptake of which may involve the endosomal sorting complex required for transport (ESCRT complex) and relevant proteins. After release, exosomes are taken up by neighboring or distant cells, and the miRNAs contained within modulate such processes as interfering with tumor immunity and the microenvironment, possibly facilitating tumor growth, invasion, metastasis, angiogenesis and drug resistance. Therefore, exosomal miRNAs have a significant function in regulating cancer progression. Here, we briefly review recent findings regarding tumor-derived exosomes, including RNA sorting and delivering mechanism. We then describe the intercommunication occurring between different cells via exosomal miRNAs in tumor microenvironmnt, with impacts on tumor proliferation, vascularization, metastasis and other biological characteristics. Finally, we highlight the potential role of these molecules as biomarkers in cancer diagnosis and prognosis and tumor resistance to therapeutics.
\end{abstract}

Keywords: Exosomal miRNAs, Cancer, Metastasis, Angiogenesis, Biomarkers

\section{Background}

In recent years, researchers and clinicians have mostly focused on the identification of cancer-specific targets and the development of targeted therapies that may efficiently kill cancer cells. Although considerable success has been achieved with regard to identifying effective small cancer-specific targets and a series of monoclonal antibodies [1]. However, obvious drawbacks exist. For example, cancers are characterized by extensive heterogeneity and a variety of subtypes, which complicates the identification of unique targets and the eradication of all tumor cells, due to clonal evolution of malignant cells. Another unresolved problem is how to increase the efficiency and accuracy of cancer-specific target molecules when delivered. In depth research of extracellular vesicles, especially exosome $(30-100 \mathrm{~nm})$, raised the intriguing possibility that exosomal cargo may be a good way to protect target molecules integrity and to enhance the

\footnotetext{
* Correspondence: zqsun82@csu.edu.cn; 1342664380@qq.com

${ }^{\dagger}$ Zhenqiang Sun and Ke Shi contributed equally to this work.

${ }^{1}$ Department of Anorectal Surgery, The First Affiliated Hospital of Zhengzhou

University, Zhengzhou 450052, Henan, China

Full list of author information is available at the end of the article
}

accuracy of delivery $[2,3]$. Cancer cells secrete at least 10 -fold more exosomes than do normal cells, and tumor-derived exosomes (TDEs) can facilitate cell-cell communication through the transport of growth factors, chemokines, microRNAs, and other small molecules [4, 5]. Moreover, profiling studies have revealed that exosomes of different cellular origin contain a unique expression profile of mRNAs and miRNAs, which may also differ from the signatures of their parent cells [6]. What's more, accumulating evidence suggests that tumor microenvironment highly contributes to metabolic rewiring of cancer cells via extracellular microvesicles, this fosters complete nutrient exploitation and favors OXPHOS of lipids and glutamine at the expense of glycolysis, thereby changing the microenvironment from a normal state to a tumor-favorable state that allows for tumor growth, invasion, and drug resistance [7]. miRNA-carrying exosomes released from immune cells, mesenchymal cells and cancer cells in the tumor environment can shuttle from donor cells to recipient cells $[8,9]$. In addition, cancer-derived miRNA-exosomes contribute to the recruitment and reprogramming of constituents associated with tumor environment [10].

(C) The Author(s). 2018 Open Access This article is distributed under the terms of the Creative Commons Attribution 4.0 International License (http://creativecommons.org/licenses/by/4.0/), which permits unrestricted use, distribution, and 
Therefore, exosomal miRNAs are likely to be applied as promising non-invasive biomarkers and potential targetable factors in cancer diagnosis and treatment.

\section{The biogenesis, release, and uptake of exosomes and exosomal miRNAs}

Exosomes are nano-vesicles present in the circulation that are involved in cell-to-cell communication and regulation of different biological processes. miRNAs are part of their cargo and are potential biomarkers [11]. As exosomes carry proteins, mRNAs and miRNAs that can be transferred from donor to recipient cells via target cell membrane fusion, these vesicles have recently been recognized as important mediators of interactions between different cells [2]. In tumor microenvironment, the process described above is indispensable for the transfer of cancer-promoting cellular contents to surrounding cells, thereby accelerating cancer progression [12]. During this process, the transfer of exosomal microRNAs to recipient cells to regulate target gene expression is particularly attractive, and knowledge of the biogenesis, release, and uptake of exosomes and exosomal miRNAs is helpful for both understanding the biological mechanism of cancer progression and further exploring therapeutic approaches [13].

Accumulating evidence supports that the biogenesis, uptake and material cargo sorting of exosomes involve the endosomal sorting complex required for transport (ESCRT complex) and relevant proteins [14]. The ESCRT complex can select the "cargo" protein labeled by ubiquitin, direct it to multivesicular bodies(MVBs), and then separate fromthe peripheral membrane in a highly conserved process that is homologous to the process of cytokinesis and virus budding [15]. Study of late endosome components, such as Alix, tumor susceptibility gene 101 (TSG101) and tetraspanins, promotesanunderstanding of exosomal origin [16].

Interestingly, it has recently been reported that miRNAs in a precursor state (pre-miRNA) associated with the processing complex (e.g., Dicer, Ago2 and TRBP) can be found inside breast cancer-derived exosomes, where they are processed into mature miRNAs, establishing a new method by which miRNAs are integrated into exosomes. In this scenario, the formation and activation of exosomal miRNAs needs to be stressed [17]. Canonically, the biogenesis of miRNAs begins in the nucleus where DNA containing miRNAs is transcribed by RNA polymerase II to generate primary miRNAs (pri-miRNAs) (Fig. 1).These pri-miRNAs are first transcribed as parts of longer molecules, up to several kilobases in length, which are processed in the nucleus into hairpin RNAs of 70-100 nt by the double-stranded RNA-specific ribonuclease, Drosha [18]. Hairpin pre-miRNAs are then transported by exportin 5 to the cytoplasm, where they undergo further processing by a double-stranded-specific ribonuclease, called Dicer. After maturation, double-stranded miRNAs converted into single-stranded miRNAs, and mature miRNAs are sorted into exosomes via different modes. In the miRISC-related pathway, a representative mode, singlestranded miRNAs are incorporated into RNA-induced silencing complex (RISC) along with argonaute (AGO2) and GW182, and primarily bind to specific messenger RNAs (mRNAs) at specific sequence motifs, predominantly within the 3' untranslated region (3'UTR); these motifs are significantly, though not completely, complementary to the miRNA. The mRNA/miRNA duplex then inhibits translation by blocking initiation or enhancing degradation of the mRNA [19]. Finally, the MVBs fuse with the cell membrane and release the intraluminal endosomal vesicles into the extracellular space, which then become exosomes. There are some studies indicate that some molecules act as a regulatory network and is responsible for the formation and secretion of exosomes in parent cells. For instance, Rab27a and Rab27b were found to function in multivesicular endosomes (MVEs) docking at the plasma membrane. The size of MVEs was strongly influenced by Rab27a and Rab27b silencing. With knockdown of Rab27 or its effectors SYTL4 and EXPH5 inhibiting secretion of exosomes in HeLa cells [20, 21]. In addition, a set of proteins encoded by genes that are not transcriptional targets of p53 were found to exit the cell via exosomes and exosome production by cells was found to be regulated by the p53 response. Its downstream effector TSAP6 was shown to enhance exosome production in cells undergoing a p53 response to stress. Thus, the p53 pathway regulates the production of exosomes into the medium [22]. Moverover, syndecan-syntenin interact directly with the ALIX protein via Leu-Tyr-Pro-X(n)-Leu motif to support the intraluminal budding of endosomal membranes, which is an important step in exosome formation [23, 24].

Rab27a and Rab27b have been reported to be associated with exosome secretion, with knockdown of Rab27 or its effectors SYTL4 and EXPH5 inhibiting secretion of exosomes in HeLa cells. In addition, both the tumor repressor protein p53 and its downstream effector TSAP6 enhance exosome production. Moreover, syndecan-syntenin interact directly with the ALIX protein via Leu-Tyr-Pro-X(n)-Leu motif to support the intraluminal budding of endosomal membranes, which is an important step in exosome formation. All of these studies indicate that a set of molecules act as a regulatory network and is responsible for the formation and secretion of exosomes in parent cells.

Experimental methodology of isolating exosomal miRNAs For implementation of the use of new biomarkers into clinical practice, the first step is to standardize exosomal measurement and to evaluate their stability. However, 


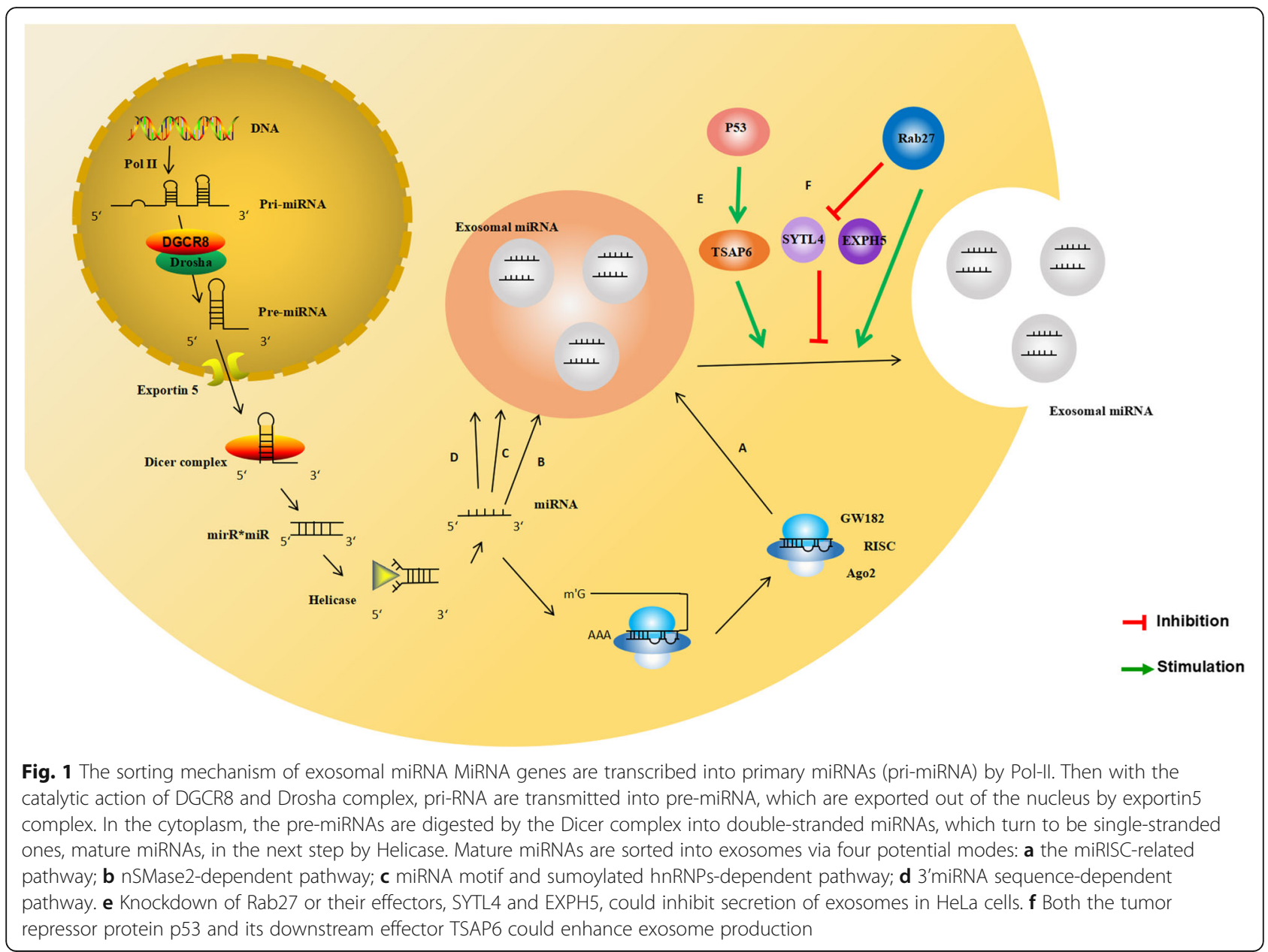

there is not a gold standard for exosome isolation. Thus far, ultracentrifugation was the popular methodology applied for their isolation because it was reproducible and could be provided optimal amounts of exosomes. The different centrifugal force and duration to isolate exosomes are easy to control, based on their density and size differences from other components in a sample, consisting of serum isolation with $100,000 \mathrm{~g}$ to $120,000 \mathrm{~g}$, urine exosome isolation with $17,000 \mathrm{~g}$, and milk exosome isolation with $12,000 \mathrm{~g}$ to $35,000 \mathrm{~g}$. While the disadvantages prevent its effectiveness, including excessive pressure suffered by exosomes during this process, lack of specificity during the precipitation, excessive time, the equipment required for isolation, and difficulties in exactly reproducing the isolation in different places. Another isolation method commonly used is size exclusion chromatography. It allows a better degree of purity and is less harmful to exosomes. Nevertheless, the high final dilution of the exosome sample makes it difficult to use them in downstream applications that require a high exosome concentration, such as the evaluation of their miRNA profile. Finally, during recent years, there has been an increase in the number of commercial kits developed for exosome isolation. Most of them are based on precipitation. Although they are not completely specific and precipitate some impurities, their rapidity and reproducibility even in different labs make them useful for future diagnosis, primarily in miRNA-based tests. Other recent publishment pointed out the importance of freezing plasma before exosome isolation, RNA isolation and qPCR for miRNAs rather than freezing exosomes before miRNA analysis, by comparing the miRNA levels obtained from exosomes isolated from fresh plasma with that from frozen one. And it was necessary to determine the inter- and intra-individual variability of healthy subjects, which could help to optimize sample size in future studies with circulating exosomes. After isolating exosomes, some researchers have developed methods for exploiting differences between tumor-associated and non-tumor exosomes surface composition. For instance, detecting cancerous exosomes from SKOV-3 ovarian tumor cells in real time by the technique of multi-parametric surface plasmon resonance (MP-SPR) to measure LXY30 binding, without a priori labeling. 
As for the experimental skill of exosomal miRNAs examination and protection, he current commonly avenue is quantitative reverse transcription polymerase chain reaction (qRT-PCR), however, this method requires highly trained experience and have the potential to generate false positive signals. Later, some groups developed PCR-free methods for exosomal miRNAs quantitation based on ratiometric electrochemistry, localized surface plasmon resonance (LSPR), and surface-enhanced Raman scattering (SERS), respectively, while the expensive instrument and complex operation have hampered their extensive application. At present, fluorescent methods have been given attention, because of their intrinsic advantages, including simple instrumentation, as well as high sensitivity and capacity to high-throughput screening.To date, several attempts have been reported using fluorescent methods to detect exosomal miRNAs with various degrees of success, as evidenced by the cationic lipoplex nanoparticles containing a molecular beacon assay, fluorescent dye-labeled molecular beacons strategies, fluorescence signal amplifiable biochip assay, and others. However, these methods employed solely responsive signal and were based on measuring the absolute change of the fluorescent intensity, which was readily perturbed by numerous experimental conditions, including thermodynamic fluctuations, nuclease degradation, and dye photobleaching. To utilize exosomal miRNAs as a diagnosis biomarker, a fluorescent system with antidisturbance should be developed, due to the complex biosystem. Surprisingly, because of the self-referencing capability, ratiometric fluorescent measurement is able to cancel out environmental fluctuations by calculating the emission intensity ratio at two different wavelengths. Recently, the practical applications of ratiometric fluorescent bioprobes has been improved. For instance, a ratiometric fluorescent bioprobe based on DNA-labeled carbon dots (DNA-CDs) and 5,7-dinitro-2-sulfo-acridone (DSA) coupling with the target-catalyzing signal amplification for the detection of exosomal miRNA-21. There was high fluorescence resonance energy transfer (FRET) efficiency between carbon dots (CDs) and DSA when the bioprobe was assembled.

After gain the exosomal miRNAs, some researches claim that a new concept for miRNA editing measurement would be necessary, which considered not only the absolute editing level of miRNA but the miRNAs modification assessed via reads per million reads mapped to miRNAs (RPM). For example, by analyzing small-RNA sequencing data from exosome samples of NSCLC patients at different stages, researchers found that editing(ED) miR-411-5p downregulated, while wild-type (WT) showed no significant difference in expression. Further study showed that miR-411-5p edited in position 5 was differentially expressed between NSCLC and normal tissue samples, indicating that the machinery that governs the export of miRNAs to extracellular space in tumor conditions may discriminate ED miRNAs differently. Thus, they thought post-transcriptional modifications in miRNAs within both tissues and circulation could both serve as potential novel biomarkers and provide additional insights into the pathogenesis of cancers.

\section{Exosomal miRNA in Cancer}

The malignant phenotypes of tumors are not only determined by cancer cells themselves but also depend on the surrounding tumor microenvironments [25]. Studies on the relationship between exosomal miRNAs and cancer begin to reveal a general picture of their ubiquitous involvement in cellular pathways from life to death, from metabolism to communication. These molecules have an undeniable role in cancer both as tumor suppressors and promoters modulating cell proliferation and migration, the epithelial-mesenchymal transition (EMT), and tumor proliferation, angiogenesis and metastasis [5]. Moreover, exosomal microRNAs can even affect the environment surrounding the tumor, influencing the extracellular matrix (ECM) as well as immune system activation and recruitment. Clearly, the influence of exosomal miRNA on cancer is somewhat similar to that of miRNA [23] (Fig. 2).

\section{miRNAs, ECM, and Cancer-associated fibroblasts (CAFs) miRNAs and ECM}

The tumor microenvironment is defined as the variety of normal cells, blood vessels, signaling molecules, and ECM that surround tumor cells [19]. The cellular components of the tumor microenvironment include endothelial cells, pericytes, fibroblasts, and immune cells [26]. Both tumor environmental cues and cell-intrinsic alterations contribute to these epigenetic changes, inducing adaptations by cancer cells that allow successful invasion of the stroma, entry and survival in lymphatic or blood vessels, spread to and colonization of distant/different organs, as well as resistance to cytotoxic drugs [27]. Cancer-associated fibroblasts(CAFs) are vital constituents of the tumor microenvironment, and their interactions with cancer cells play a major role in mediating their formation and activation $[28,29]$.

CAFs isolated from cancer patients have a morphology and function that differs from that of normal fibroblasts (NFs). CAFs have been shown to promote the invasion and growth of tumor cells [30]. CAFs produce growth factors (e.g., vascular endothelial growth factor (VEGF)) and cytokines (e.g., TGF $\beta$, IL-6, IL-10) that activate the adjacent ECM, contributing to cancer cell growth. Additionally, CAFs are the primary source of an altered ECM, containing fibronectin and collagen, and also promote tumor growth [31]. CAF-secreted factors include proinflammatory cytokines, typically IL-1 $\beta$ and IL- 8 


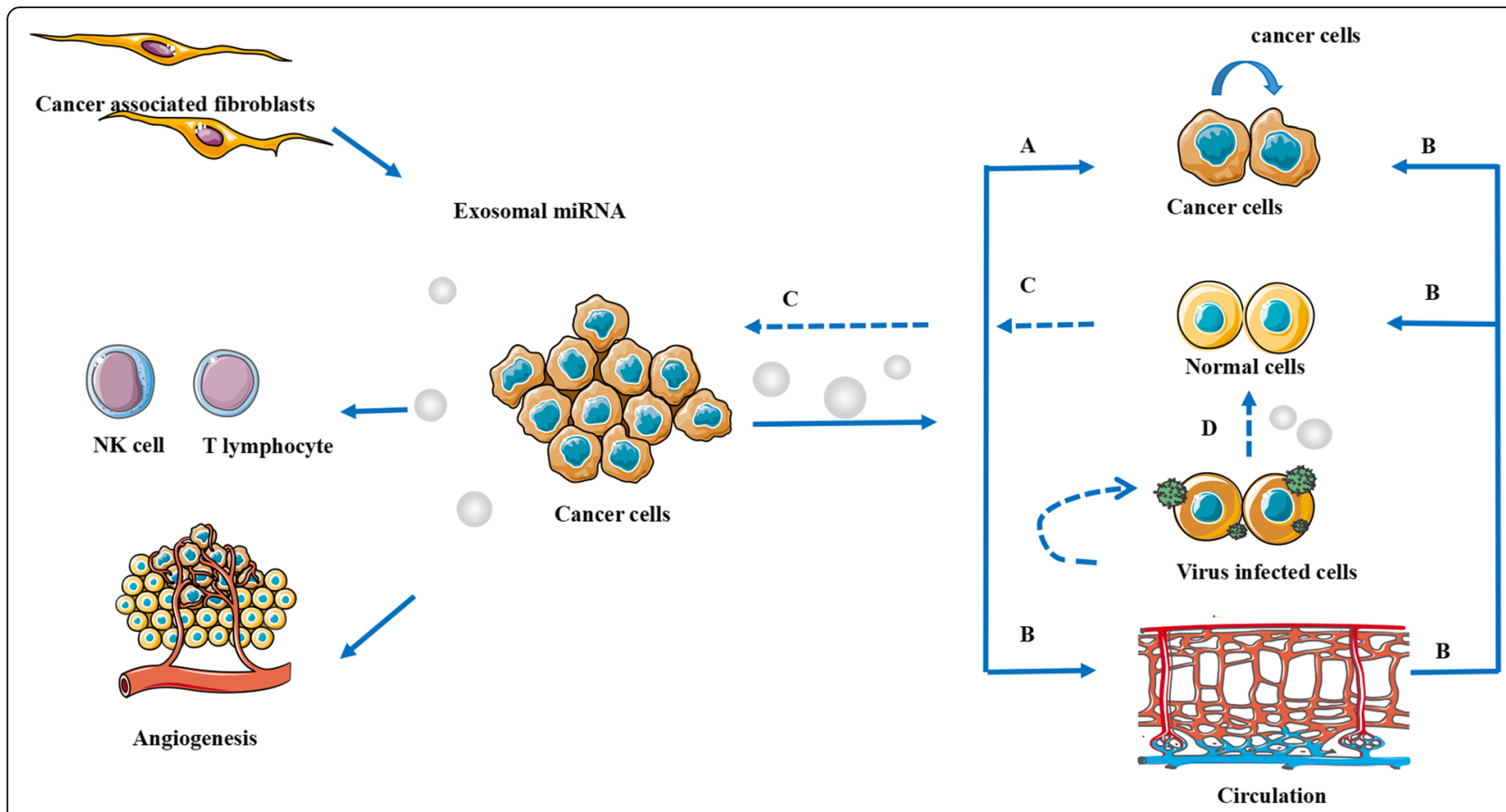

Fig. 2 Exosomal miRNA in Cancer. a The first general mechanism is that cancer cells export exosomal miRNA to parent surrounding cancer cells. b The second general mechanism is that primary tumor cells can communicate with other cells via exosomal miRNAs in the tumor microenvironment. $\mathbf{c}$ The third general mechanism is that exosomes derived from normal cells alter the behavior of tumor cells. $\mathbf{d}$ The forth general mechanism is that exosomes derived from cells infected with virus to influencr normal cells oncology and themselves

typically, which are associated with pro-tumorigenic effects. SDF- $1 \alpha$, a prominent chemokinesecreted by CAFs, promotes proliferation, by signaling through chemokine (CXC) receptor 4 (CXCR4) [32]. NFs have been shown to inhibit tumor growth, unlike CAFs, and it has recently been reported that exosomal miRNAs might convert NFs into CAFs for tumor survival. Nonetheless, how this communication promotes activation of NFs into CAFs remains poorly understood.

Recent studies have demonstrated that pancreatic cancer cells secrete exosomal miR-155 to activate NFs. This phenomenon might be related to miR-155-mediated downregulation of its target TP53INP1 [33]. Moreover, previous studies have shown that highly metastatic hepatocellular carcinoma (HCC) cells secrete exosomal miR-1247-3p targeting B4GALT3, leading to activation of $\beta 1$-integrin-NF- $k B$ signaling in fibroblasts. Activated CAFs further promote cancer progression by secreting proinflammatory cytokines, including IL-6 and IL-8 [34]. In addition, the relationship between exosomal miRNAs and CAFs activation is unlikely to be unidirectional. A CAF-like phenotype inducible by tumor cells through exosome-mediated delivery of miR-9 was reported in triple-negative breast cancer. Interestingly, miR-9 is also released by NFs and transferred to tumor cells [30]. All of these studies indicate that exosomal miRNA and their targets act as a regulatory network responsible for transformation of the tumor microenvironment.

\section{Exosomal miRNAs and tumor immunity}

Emerging evidences suggests that tumor-derived exosomes participate in tumor immune escape by delivering immunosuppressive molecules and factors [35]. Exosomal miRNAs are carriers of information that is able to reprogram functions of immunologically active factor and immune target cells, such as dendritic cells (DCs), natural killer (NK) cells, and T lymphocytes et al. [36].

It has been shown that proinflammatory conditions might promote tumorigenesis [37]. DCs are crucial regulators of the immune system that initiate immunity or immunological tolerance depending on their state of activation [38].When activatedupon exposure to danger signals from pathogens or damaged tissue, DCs trigger the activity of pattern recognition receptors, such as Toll-like receptors (TLRs) [39]. Upon TLR stimulation, DCs upregulate costimulatory molecules and proinflammatory cytokines to stimulate $\mathrm{T}$ lymphocytes and initiate immune responses [40]. Non-small cell lung cancer (NSCLC) secretes an abundance of exosomes containing miR-21 and miR-29a, which can bind to TLRs to induce protumoral inflammation, leading to tumor growth and metastasis [41]. Overexpression of miR-203 in pancreatic 
adenocarcinoma has a similar effect on TLR4 as miR-21 and miR-29a [42]. Moreover, pancreatic cancer-derived exosomes transfer miRNAs toDCs and inhibit Regulatory factor $\mathrm{X}$-associated protein(RFXAP) expression via miR-212-3p, inducing MHC II downregulation and immune tolerance of DCs [36].

Exosomal miRNAs also play a role in the biology of NK cells and T lymphocytes. NKs are a sub-population of T cells with a role as tumor cell killer, which can produce a series of antitumor cytokines, including IL-4, IFN- $\gamma$, FasL, IL-13, and perforin [43]. Importantly, their efficiency is abrogated by exposure to TGF- $\beta$. Meanwhile, TGF- $\beta$-inducible miR-183 silences tumor-associated natural killer cells by targeting and repressing DNAX activating protein [44]. Moreover, hypoxia-inducible miR-210 regulates the susceptibility of tumor cells to lysis by cytotoxic $\mathrm{T}$ cells. Hypoxic tumor-derived microvesicles negatively regulate NK cell function by a mechanism, involving TGF- $\beta$ and miR-23a transfer [45].

Besides, the process, exosomic miRNAs acting on NKs immune activity and then inducing tumor resistance to immunology, involves in many-sided, many-targeted, many-factored effect. Here we focus on some emblematical miRNAs from TDE shown in Table 1.

\section{Exosomal miRNA and tumor proliferation}

Malignant cells have the ability to transfer genetic information to other cells in the tumor microenvironment through exosomes. Some of the exosomic miRNAs transported between donors and recipients are shown in Table 2, indicating that exosomal miRNAs contribute to cancer cell proliferation, angiogenesis, metastasis, drug resistance and tumor inhibition.

Proliferation is an important aspect of cancer development and progression that is manifested by altered expression and/or activity of cell cycle-related proteins. Constitutive activation of many signal transduction pathways also stimulates cell growth [46]. miR-584-derived exosomes from HCC cells target TGF- $\beta$-activated kinase-1 (TAK1) and associated signaling, leading to TAK1 downregulation. TAK1 is an essential inhibitor of hepatocarcinogenesis and has a direct effect on cancer progression through repression of the telomerase reverse transcriptase gene. That is, miR-584 has an indirect promoting effect on tumor proliferation [47]. Some other findings suggest that miR-125a from TDEs as a result of diaphanous-related formin-3 (DIAPH3) loss or growth factor stimulation may condition the tumor microenvironment through multiple mechanisms, including the proliferation of cancer cells and suppression of tumor-infiltrating immune cells [48]. Still another research showed that miR-1246 packaged in exosomes from 2 Gy-irradiated BEP2D cells could act as a transfer messenger and contribute to DNA damage by directly repressing the DNA ligase 4 (LIG4) gene, which inhibited the proliferation of nonirradiated cells [49].

The stages of tumor proliferation do not have obvious boundaries, and each stage of development does not exist independently. Tumor proliferation is often a contributing factor to the further development of tumor angiogenesis and metastasis.

\section{Exosomal miRNA and tumor angiogenesis}

Tumor angiogenesis comprises several steps: enzymatic degradation of the vessel's basement membrane, endothelial cells proliferation, migration, sprouting, branching, and tube formation. In tumor microenvironment, exosomes released by different cell types have been shown to function as positive mediators during this process [50], including mesenchymal stem cells, stromal cell, endothelial cells [51].Considerable attention is now focused on the role of miRNAs secreted by TDE acting on the process of vascularization.

Hypoxia is one of the main factors involved in tumor angiogenesis and can affect the activity of various substances and promote expression of exosomal miRNAs. Previous studies have demonstrated that increases in tissue inhibitor of metalloproteinases-1 (TIMP-1) upregulates miR-210 by inducing pro-tumorigenic PI3K/AKT/HIF-1 signaling. Subsequent downregulation of miR-210-targeted

Table 1 miRNAs involved in the line of communication cancer-immune

\begin{tabular}{|c|c|c|c|c|c|}
\hline Immuno & Exosomal miRNA & Involved molecule & Involved other molecules & Function & Ref. \\
\hline \multirow[t]{2}{*}{ DCs } & miR-203 & TLR4 & TNF-a, IL-12 pathway & $\begin{array}{l}\text { DCs dysfunction in pancreatic } \\
\text { cancer }\end{array}$ & {$[42]$} \\
\hline & miR-212-3p & RFXAP & / & $\begin{array}{l}\text { Immune tolerance of DCs in } \\
\text { pancreatic cancer }\end{array}$ & [36] \\
\hline \multirow[t]{7}{*}{ Lymphocytes } & miR-183 & DAP12 & TGF $\beta$ & NK & [94] \\
\hline & miR-210 & NKG2D & TGF $\beta 1$ & NK & [45] \\
\hline & miR-23 & CD107a & / & NK & [95] \\
\hline & miR-20a & MICA/MICB & NKG2D & NK & [96] \\
\hline & miR-10b & MICB & / & NK & [97] \\
\hline & miR-92a & / & FasL, INF- $Y$ & NKT & [98] \\
\hline & miR-214 & PTEN & $\mathrm{IL}-10$ & T cell & [99] \\
\hline
\end{tabular}




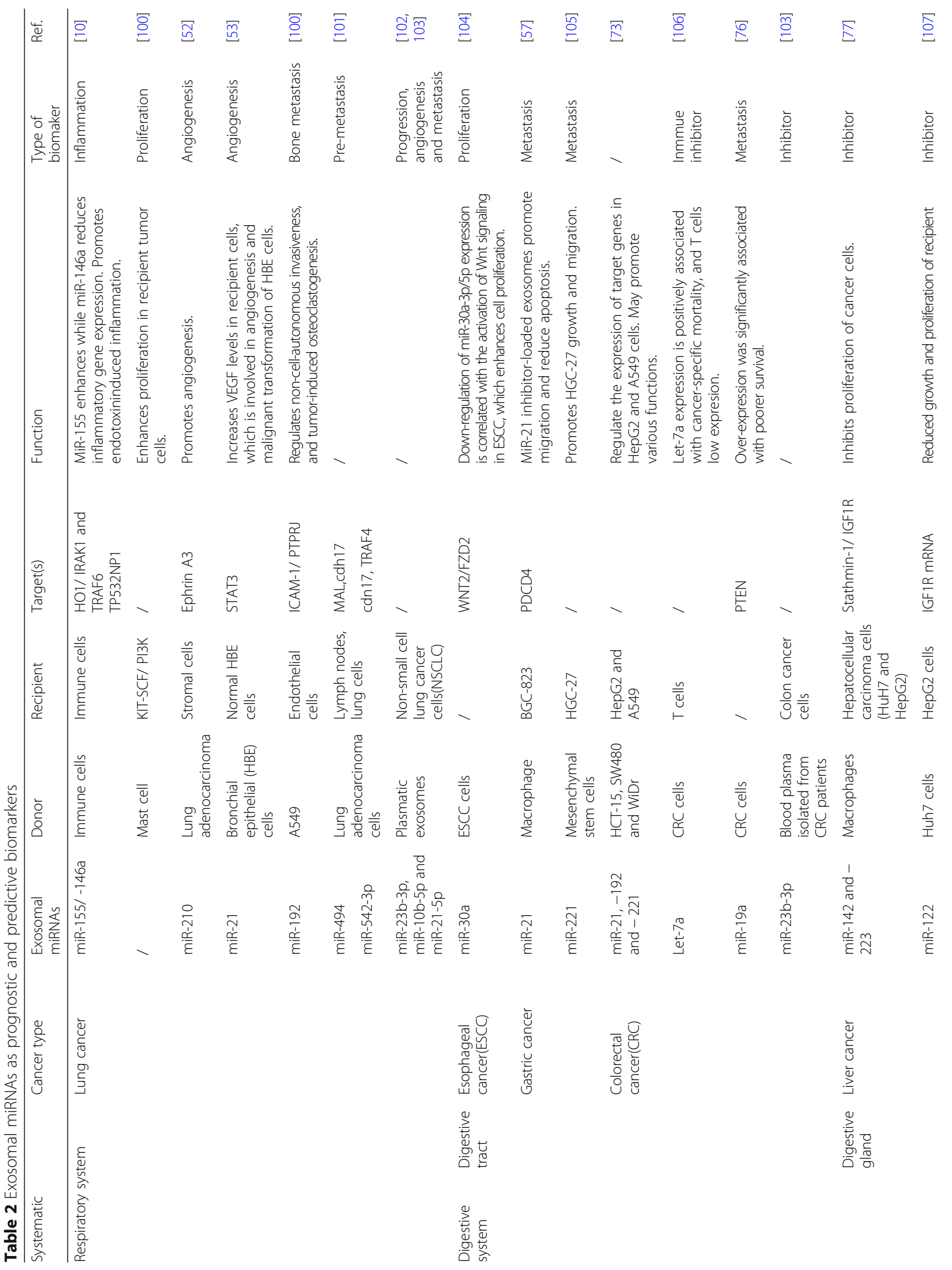




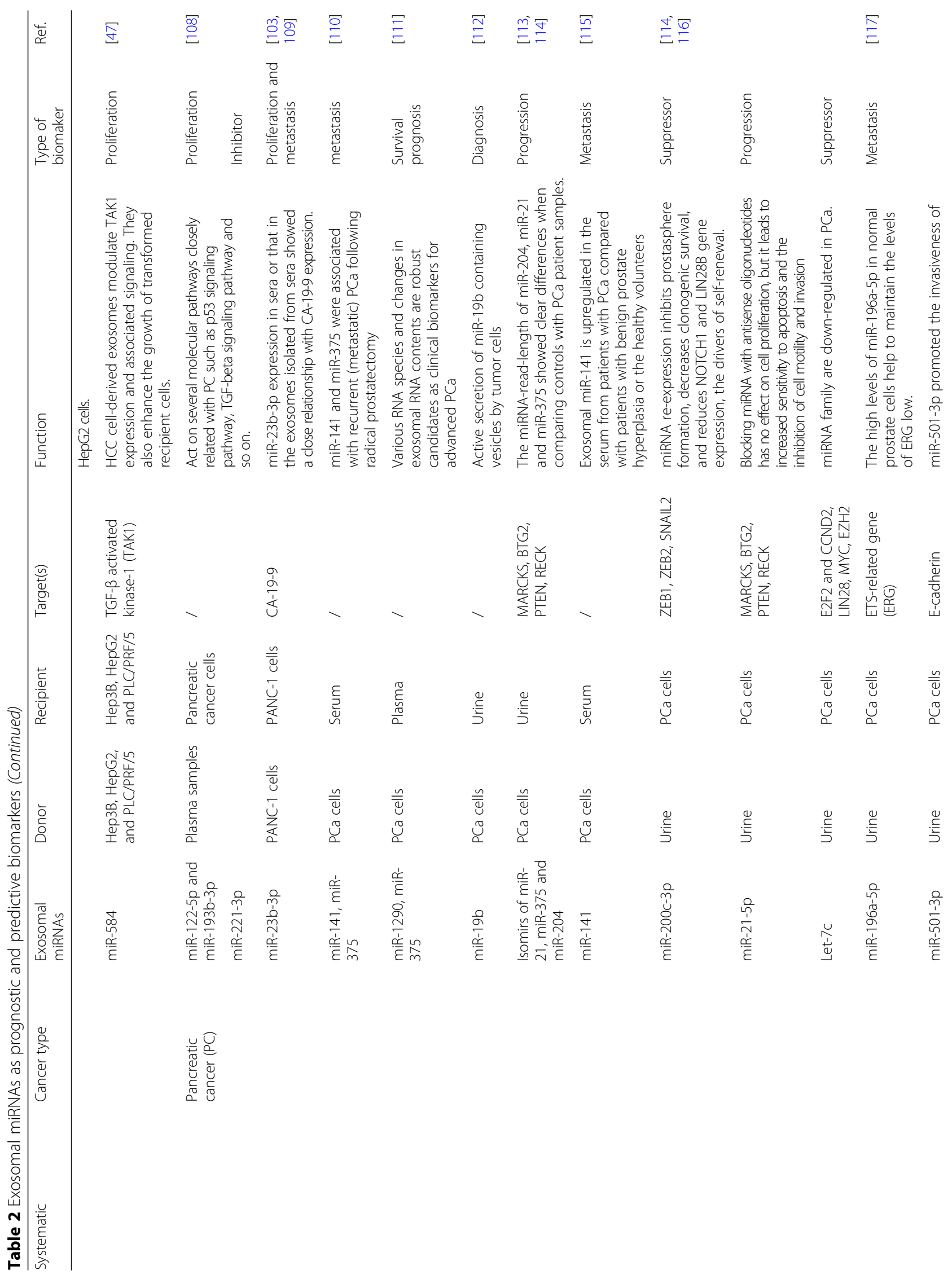




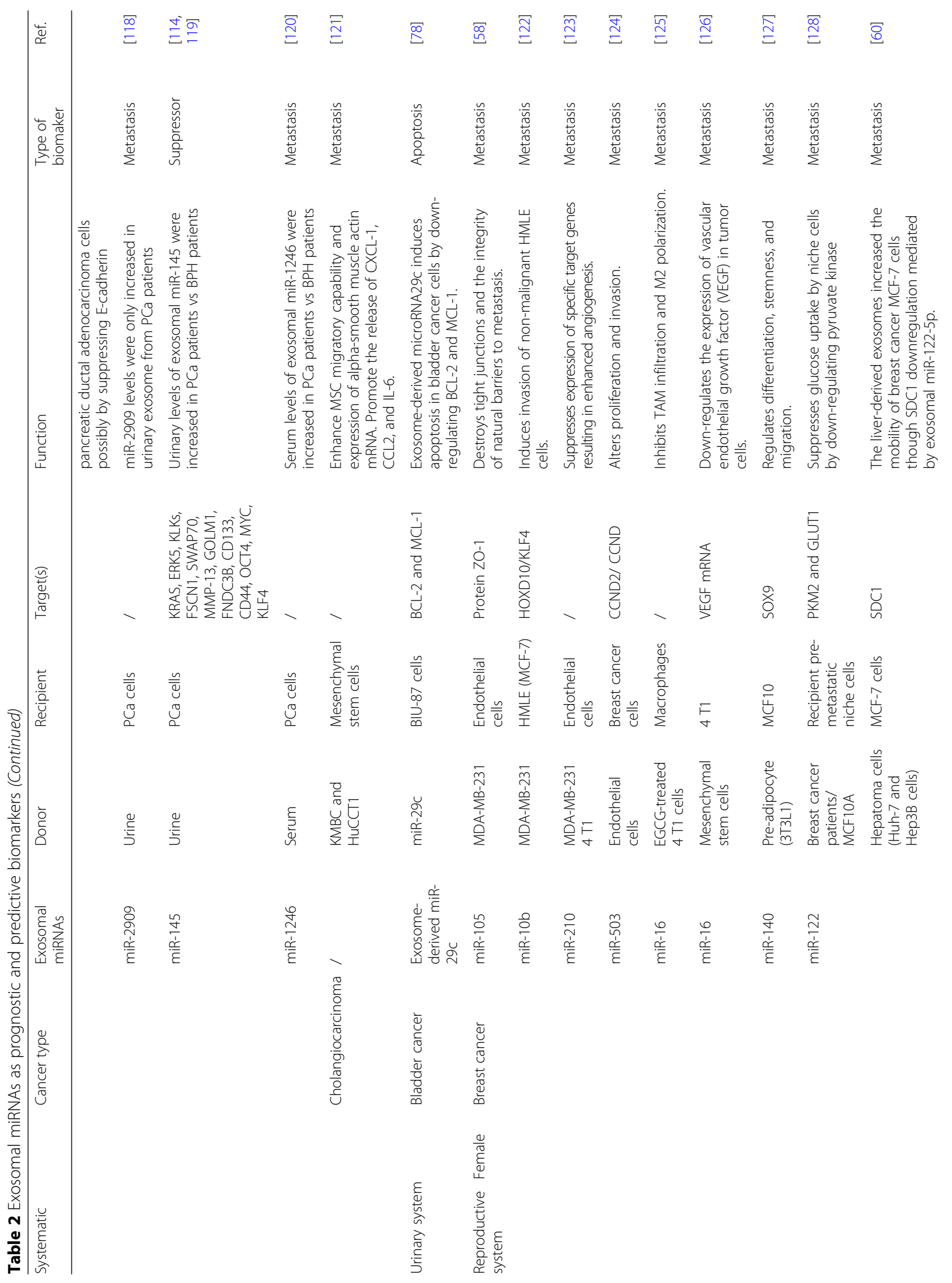




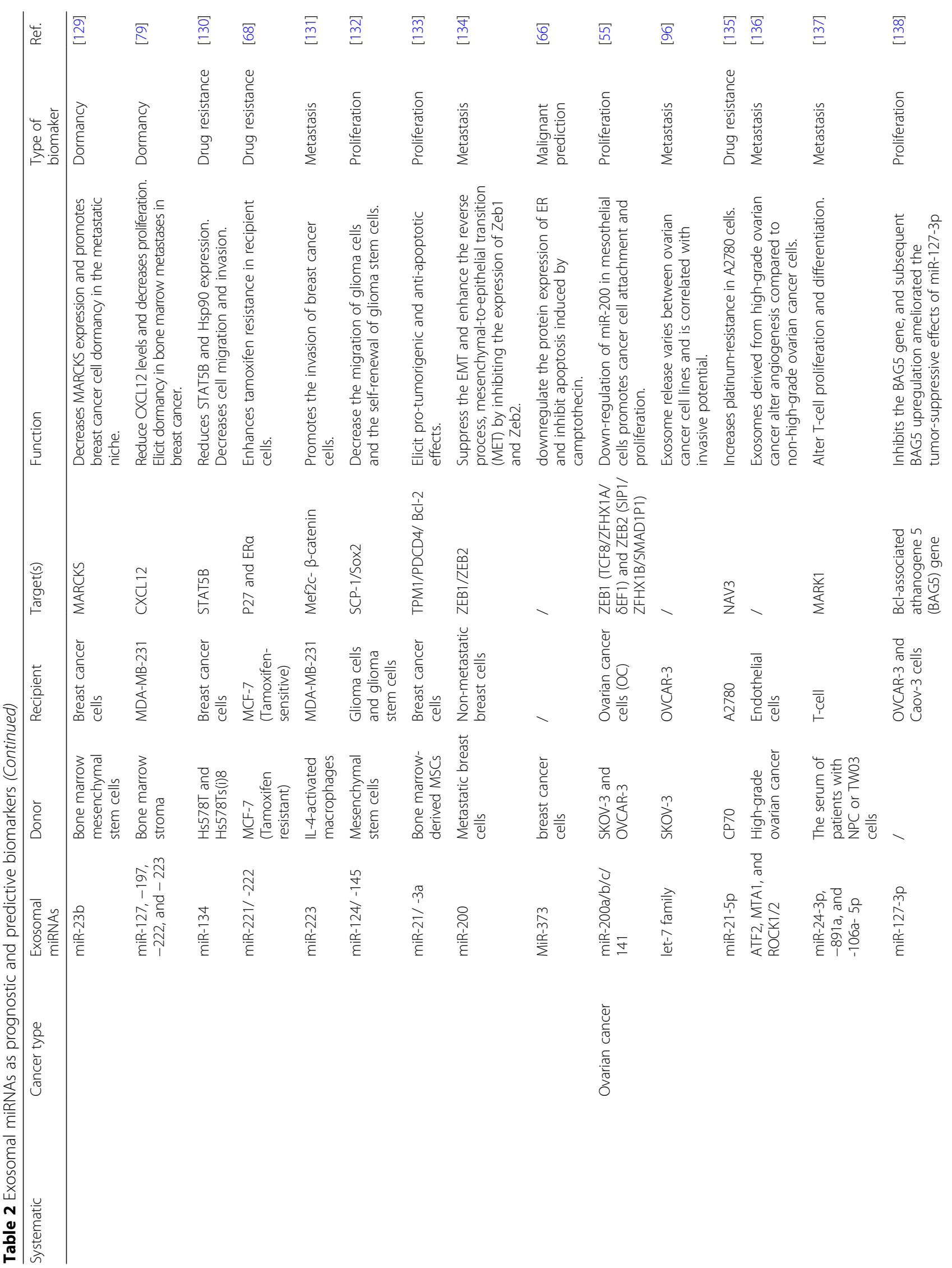




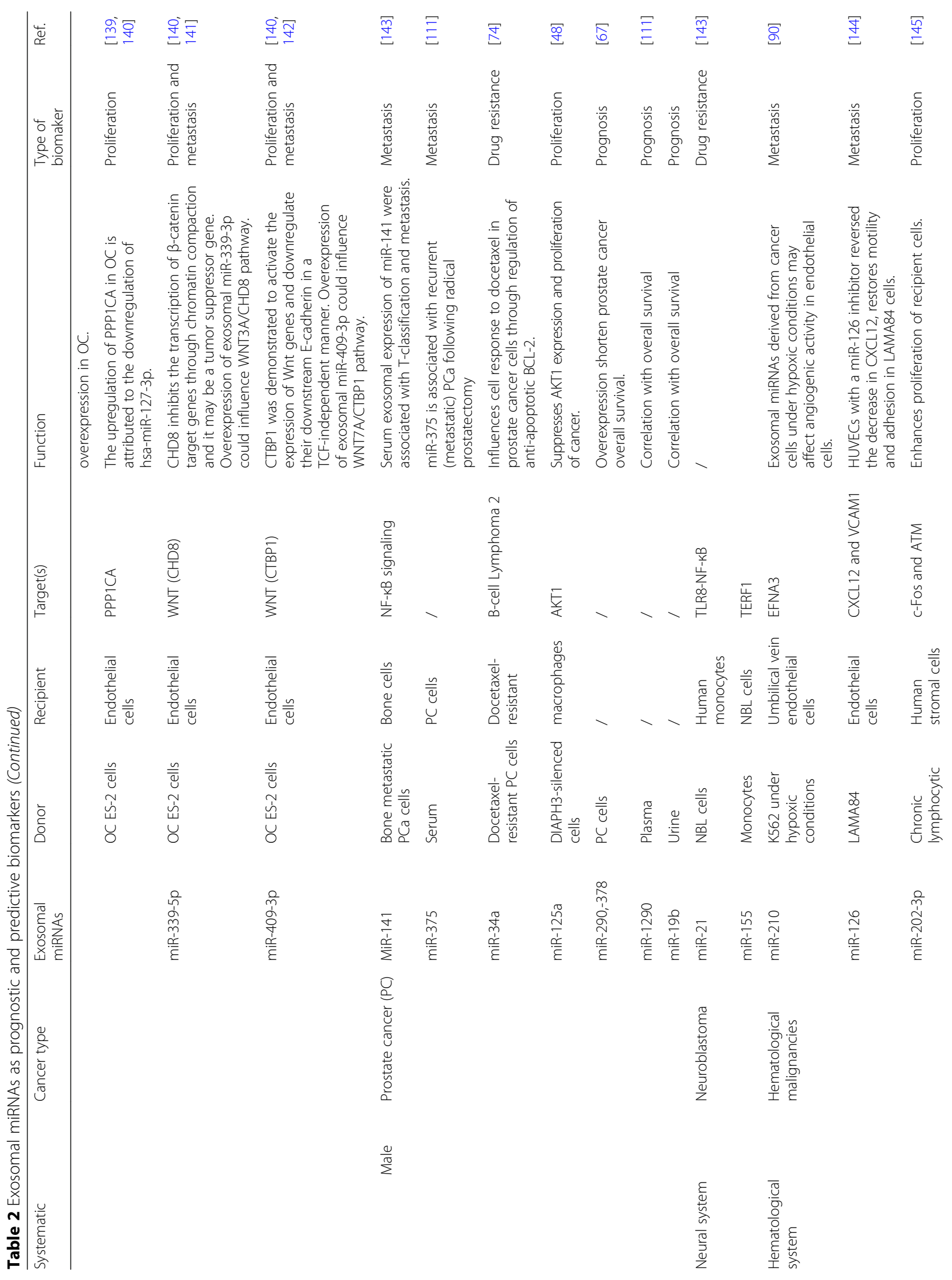


Sun et al. Molecular Cancer (2018) 17:147

Page 12 of 19

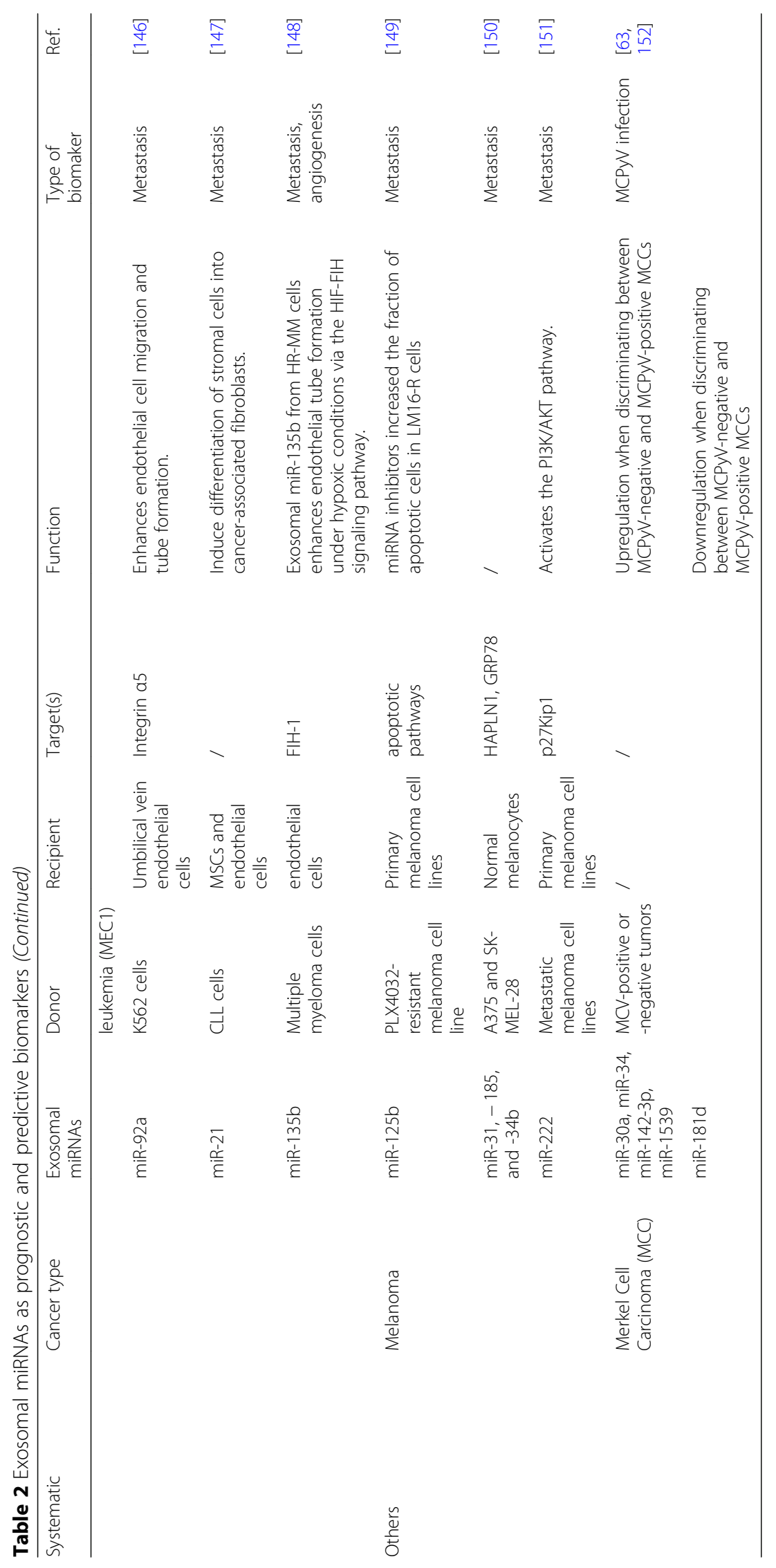


proteins results in increased pro-angiogenic properties of exosomes released by TIMP-1-overexpressing cells and thus contributes to a new mode of action by which TIMP-1 can support lung cancer progression [52]. In addition to miR-210, researchers have found that miR-21 in exosomes leads to STAT3 activation, which increases VEGF levels in recipient cells and leads to angiogenesis and malignant transformation of human bronchial epithelial (HBE) cells [53].

\section{Exosomal miRNA and tumor metastasis}

The metastatic process involves manipulation of the cellular microenvironment to optimize conditions for deposition and growth both locally and at a distance [54]. Intercellular communication can occur through various signaling molecules. Many groups have confirmed that tumor-derived exosomes are involved in the different steps of the metastatic cascade. For example, EMT is a complex molecular and cellular process involved in tissue remodeling that has been extensively studied as a facilitator of tumor progression. The miR-200 family inhibits EMT and cancer cell migration by directly targeting the E-cadherin transcriptional repressors ZEB1 and ZEB2 [55].Based on the researches, the mechanism by which miRNAs packaged by TDEs influence tumor metastasis needs to be further explored [56].

Studies have reported four general mechanisms of exosomal miRNA delivery during tumor development in the microenvironment [57]. First, less invasive tumor cells can take up miRNAs delivered from invasive tumor cells via TDEs, which may prompt worsening of a primary tumor. For example, metastatic breast cancer likely promoted cell invasion via release of exosomal miR-10b by the primary tumor into the culture environment of surrounding normal cells. This role of miRNAs packaged by TDEs acting on neighboring cells to transmit a message (produced by a donor cell and taken up by a recipient cell) resembles a paracrine mechanism of intercellular communication [56] (Fig. 2 -a).With respect to the second mechanism, primary tumor cells can communicate with other cells via exosomal miRNAs in the tumor microenvironment. For example, by downregulating tight junctions and destroys the barrier function of endothelial monolayers, cancer-secreted miR105expressed and secreted by metastatic breast cancer cells induces vascular permeability and promotes metastasis [58]. miRNAs have been reported to enter the circulatory system and travel to distant organs to deliver their message by targeting their recipient cells, emphasizing the potential of miRNAs to act as signals involved in preparing a distant site for tumor proliferation [59] (Fig. 2-b). A third mode of communication involves exosomes derived from normal cells or routine biological process that can alter the behavior of tumor cells. For example, after metastasis to the brain, but not to other organs, human and mouse tumor cells regulated by microRNAs from brain astrocytes both lost PTEN expression [50]. Another example is the exosomal level of miR-122-5p was increased upon hepatoma cell damage treated by apoptotic agent and then increased cell mobility by SDC1 downregulation [60].The last mode focus on some tumor caused by viral infections. The cells infected by virus released aberrant quality and quantity of exosomal miRNA, leading more health cells and themselves to precancerous conditions. For example, in the Burkitt Lymphoma Mutu Cell Lines, Epstein-Barr virus (EBV) infection in type III latency modulates the biogenesis of exosomes and expression profile of exosomal miRNAs, such as miR-877 [61], which may contribute to the induction of EBV-associated tumors by modulating cell and virus functions [62].Some other studies showed that Merkel cell polyoma virus seems to be the major causal factor for Merkel cell carcinoma (MCC). By comparing $\mathrm{MCPyV}$ positive cells with negative ones, miR-181d as a tumor suppressor was downexpressed in MCPyV-positive cells [63]. (Fig. 2-c).

Organ-specific metastasis is a multi-step and complicated process that includes tumor-host crosstalk among cells as well as communication between cells. Moreover, the crucial role of the tumor environment, including signaling and key molecules required for tumor metastasis, cannot be ignored.

\section{Exosomal miRNA and clinical implications}

Exosomal miRNA as a predictor of tumor response to treatment

Primary acquired resistance to chemotherapy, radiotherapy and targeted therapies remains a major stumbling block in cancer treatment [64, 65]. The key signaling pathway components in drug response, involving drug targets, transporters, and cell cycle- and apoptosis-related components, include several functional proteins that can be affected by miRNA expression [66]. Exosomes can be regarded as vehicles for loading miRNAs, targeting and combining fundamental genetic molecules in the pathways mediating chemotherapy, radiotherapy and targeted therapies.

Recent studies have reported that treatment of prostate cancer with paclitaxel (PTX) often fails due to the development of chemo-resistance caused by downregulation of the tumor suppressor gene miR-34a. This miRNA has been suggested to be an intracellular and exosomal predictive biomarker for response to docetaxel with clinical relevance to prostate cancer progression by regulating the anti-apoptotic gene BCL-2 [67]. Other researchers have reported that tamoxifen-sensitive breast cancer cells can acquire drug resistance after internalizing exosomes derived from tamoxifen-resistant breast cancer cells. The underlying mechanism involves inhibition of P27 and ER $\alpha$ expression in tamoxifen-sensitive cells by miR-221/222 carried within the transferred 
exosomes [68]. Furthermore, the research on exosomal miR-21 as biomarker of treatment outcome in non-small cell lung cancer (NSCLC) has also been developed. It was revealed that the high level of miR-21 related to the acquired resistance to the treatment consisting of epidermal growth factor receptor (EGFR) and tyrosine kinase inhibitors (TKIs) [69]. The radio sensitivity mediated by PI3K/ Akt pathway represents also an aspect controlled by miR-21, and the inhibition of miR-21 improved the sensitivity to radiotherapy [70], which would be advantages of miR-21 as a useful predictor of the therapeutic response, and constructive, worse outcome [71].

Therefore, some exosomal miRNAs can provide information about the identity of the cell type from which they are derived, the target, and the cellular state, including therapy resistance. Accordingly, it is possible to monitor and regulate tumor resistance, and achieve personalized therapy.

\section{Exosomal miRNAs as fascinating possibility for tumor biomarker}

The cargo of exosomes is specific for the parental cells and the conditions in which they produce them, which implied that circulating miRNAs in exosomes had the potential toserve as prognostic and predictive biomarkers [72]. This review focuses on the biological characteristics of exosomal miRNAs as cancer surrogate biomarkers. Different miRNAs from tumor-related (TR) exosomes have been detected as biomarkers in the plasma of tumor patients.

As the potential role of tumor diagnosis, the results of a meta-analysis suggested that miR-21-containing circulating exosomes, which can also be detected in feces, in plasma may be a reliable and non-invasive biomarker for colorectal cancer diagnosis [73]. Moreover, recent studies have claimed that circulating exosomal miRNA-373 is upregulated in receptor-negative breast cancer patients [74]. Additionally, miR-1290 and miR-375 upregulation might indicate poor overall survival in castration-resistant prostate cancer [75], and exosomal miR-19a cluster expression level in serumarecorrelated with recurrence in colorectal cancer [76].

In addition to tumor markers, exosomal miRNAs can also act as tumor development inhibitors, with a fascinating possibility for tumor therapy. The correlation between miRNAs from TDEs and immunology is ubiquitous, further demonstrating differences between tumor phenotypes. Thus, secreted miRNAs may be considered a type of immune cell effector. For example, transfer of miR-142 and miR-223 influences post-transcriptional regulation of proteins in HCC, including decreased expression of reporter proteins and endogenously expressed stathmin-1 and insulin-like growth factor-1 receptor. This ultimately inhibits proliferation of these cancerous cells, suggesting that miR-142 and miR-223 may act as inhibitors of tumor treatment [77]. Furthermore, exosome-derived miR-29c induces apoptosis in bladder cancer cells by downregulating BCL-2 and MCL-1 [78], and some exosomal miRNAs, such as miR-127 and miR-197, can elicit dormancy in tumor metastasis and proliferation, decreasing proliferation and eliciting dormancy in bone marrow metastasis of breast cancer. All of these molecules may inhibit tumor treatment [79]. To utilize exosomal miRNAs as a diagnosis biomarker, a fluorescent system with antidisturbance should be developed, due to the complex biosystem. Surprisingly, because of the self-referencing capability, ratiometric fluorescent measurement is able to cancel out environmental fluctuations by calculating the emission intensity ratio at two different wavelengths [80]. Recently, the practical applications of ratiometric fluorescent bioprobes has been improved. For instance, a ratiometric fluorescent bioprobe based on DNA-labeled carbon dots (DNA-CDs) and 5,7-dinitro-2-sulfo-acridone (DSA) coupling with the target-catalyzing signal amplification for the detection of exosomal miRNA-21. There was high fluorescence resonance energy transfer (FRET) efficiency between carbon dots (CDs) and DSA when the bioprobe was assembled [81].

To date,there is increasing evidence for the roles of TDEs. Considering that compared with total circulating RNAs, exosomes typically target specific cells, detection of exosomal miRNAs in clinical examination appears reasonable, which might assist physicians with predicting cancer prognosis [82].

\section{Exosomal miRNA delivery system: Opportunities and challenges}

In previous researches, miRNAs encased in TDEs are more likely to escape attack by immune systemand able to cross the blood-brain barrier. Moreover, exosomes are likely to protect their cargo from clearance or damage by the complement fixation or macrophages due to their double-layered membrane and nanoscale size, thus prolong their circulation half-life and enhancing their biological activity [83]. Exosomes can deliver miRNAs to target recipient cells with a distinctcomposition of proteins and lipids on their surface. In addition, exosome membrane is rich in sphingomyelin, ceramide, and cholesterol, which help to distinguish exosomes from the cell membrane and facilitates their uptake by recipient cells. As a consequence, exosomes always succeed, even though they sometimestake a longer path to reach their target [84].

Differential experimental skills have been employed in an attempt to purify reticulocyte exosomes from tissue culture medium, and new methods for exosome purification were developed to reduce the cell media required,thus enhancing maneuverability and improving efficiency [85]. In addition, the abovementioned studies 
have found that Dicer and Ago2, the key components of miRNA processing, are functionally present in exosomes, suggesting that miRNA might not be the only cargo carried by EVs [18]. Another challenge is how to load the desired cargo. For example, miRNA can be efficiently encapsulated into exosomes by manipulating exosome-producing cells to overexpress cargo miRNA. By usinga cell-specific protein present in the membrane of the exosomes,these encapsulated miRNAs were delivered to EGFR-expressing breast cancer cells. However, researchers were unable to encapsulate miRNA into HEK-293-derived exosomes using electroporation [86]. In addition to technological issues, exosomes have the potential to spread numerous pathogens. Many pathogenic factors, including viral proteins and fragments of viral genomes, can be incorporated into exosomes derived from virus-infected cells, and exosome-mediated delivery of these factors has been shown to affect the immune responses to infection and to modulate recipient cells responses. For example, HIV-1 achieves cell entry via exosome-mediated transfer of chemokine receptor 5 to recipient cells [87]. There are still some limitationsregarding encapsulated miRNAs in the exosomal miRNA delivery system. As cell-based delivery vehicles, exosomes sufficiently deliver their functional message to recipient cells without negative side effects; thus, exosomes are attracting attention in molecular medicine as potential modulators of disease-mediated processes. Nevertheless, we cannot ignore the problems of miRNA in itself, some have shown that imported miRNA results in little cellular toxicity and has substantial effects on miRNA regulation in recipient cells, for example, exosomal transfer of miR-155 inhibitors and mimics to macrophages [88].

Currently, a growing number of evidence reveals that exosomal miRNAs were highly disease-related not only with tumor but other diseases, and both sides will improve prominently by interoperability of knowledge. For example, miR-21-5p, miR-29a-3p and miR-126-3p are involved in pathways related to diabetic kidney disease (DKD) pathogenesis, such as apoptosis, fibrosis, and extracellular matrix accumulation. They seem to be dysregulated in patients with different stages of DKD, constituting potential biomarkers of this disease [89]. At the same time, miR-21 and miR-29a act in NSCLC tumor growth and metastasis [41], and miR-126 promotes the Hematological malignancies metastasis [90]. Some other studys showed that high-glucose(HG) exosomes contained high levels of miR-28, miR-31a, and miR130acompared to exosomes derived from non-HG-stimulated Schwann cells, which might promote development of diabetic peripheral neuropathy. Schwann cells are the most abundant myelinated cells [91]. Herein, a potential point on whether the high release of these exosomal miRNA would influence tumor development need to be explored. Some other study held that the transport of miRNAs, within or in association with exosomes, may provide a distant and potentially more bioactive pool of circulating miRNAs compared to those that are riboprotein bound. Currently, however, there is no evidence to suggest functional differences between exosomal miRNAs and free ones, nor is it known whether exosomal and free miRNAs are differentially regulated in response to stimulation. Future studies need to classify whether miRNA packaging into exosomes and exosomal uptake is a selective/stimulus dependent process [92].

Thus, applying exosomal miRNAs to clinical treatment is a challenging but intriguing endeavor that requires further exploration by researchers and clinicians.

\section{Conclusion}

To successfully develop advanced therapeutic options for the treatment of cancer, exosomal miRNAs should not be disregarded. Based on the specific function of miRNA delivered by TDE, we will be able to counteract pro-tumorigenic and pro-metastatic signals that contribute to the growth, spread, and drug resistance of tumor cells by potentially engineering the miRNA and protein cargo of exosomes or by interfering with their trafficking.However, further study is required to cause tumor cells to forsake "heresy" and return to the "truth".Therefore, future efforts should focus on identifying the right correct of TDE-mediated immune escape and TDE-mediated tumor resistance to avoid the disadvantages of exosomal miRNAs [93]. Moreover, an effective selective mechanism for exosomal miRNA delivery system and technologies for miRNA mimic-importing TDEs can also be expected.

\section{Abbreviations}

3'UTR: 3' untranslated region; AGO2: Argonaut; CAFs: Cancer-associated fibroblasts; CDs: Carbon dots; CRC: Colorectal cancer; CXC: Chemokine; CXCR4: Chemokinereceptor 4; DCs: Dendritic cells; DIAPH3: Diaphanousrelated formin-3; DKD: Diabetic kidney disease; DNA-CDs: DNA-labeled carbon dots; DSA: 5,7-dinitro-2-sulfo-acridone; EBV: Epstein-Barr virus; ECM: Extracellular matrix; ED: Editing; EGFR: Epidermal growth factor receptor; EMT: Epithelial-to-mesenchymal transition; ESCC: Esophageal cancer; ESCRT Complex: Endosomal sorting complex required for transport; FRET: Fluorescence resonance energy transfer; HBE: Bronchial epithelial; HCC: Hepatocellular carcinoma; LSPR: Localized surface plasmon resonance; MCC: Merkel cell carcinoma; MCC: Merkel cell carcinoma; MET: Mesenchymalto-epithelial transition; miRNAs: MicroRNAs; mRNA: Messenger RNA: MVB: Multivesicular bodies; NFs: Fibroblasts; NK: Natural killer cells; NSCLC: Non-small cell lung cancer; nSMase2: Sphyngomyelinase 2; PC: Pancreatic cancer; pri-miRNAs: Primary miRNAs; PTX: Paclitaxel; qRTPCR: Quantitative reverse transcription polymerase chain reaction; RFXAP: Regulatory factor $X$-associated protein; RISC: RNA induced silencing complex; RPM: Reads per million reads mapped to miRNAs; SERS: Surfaceenhanced Raman scattering; TAK1: TGF-Bactivated kinase-1; TDEs: Tumorderived exosomes; TKIs: Tyrosine kinase inhibitors; TLRs: Toll-like receptors; VEGF: Vascular endothelial growth factor; WT: Wild-type

\section{Funding}

This study was supported by the National Natural Science Foundation of China (81560385), the Medical Scientific and Technological Research Project of Henan Province (201702027), Youth Innovation Fund Project of The First Affiliated Hospital of Zhengzhou University (YNQN2017035), and the China Postdoctoral Science Foundation (2017 M610462). 


\section{Authors' contributions}

ZQS, WTY and JBL provided direction and guidance throughout the preparation of this manuscript. ZQS, SXY wrote and edited the manuscript. QBZ, GXW, ZL, JMS and ZYZ reviewed and made significant revisions to the manuscript. JZX, KKX and YC collected and prepared the related papers. All authors read and approved the final manuscript.

\section{Ethics approval and consent to participate}

Not applicable.

\section{Consent for publication}

Not applicable.

\section{Competing interests}

The authors declare that they have no competing interests.

\section{Publisher's Note}

Springer Nature remains neutral with regard to jurisdictional claims in published maps and institutional affiliations.

\section{Author details}

'Department of Anorectal Surgery, The First Affiliated Hospital of Zhengzhou University, Zhengzhou 450052, Henan, China. ${ }^{2}$ Department of Plastic Surgery, The First Affiliated Hospital of Zhengzhou University, Zhengzhou 450052, Henan, China.

\section{Received: 31 January 2018 Accepted: 25 September 2018}

Published online: 11 October 2018

\section{References}

1. Scott AM, Wolchok JD, Old LJ. Antibody therapy of cancer. Nat Rev Cancer. 2012;12:278

2. Behera J, Tyagi N. Exosomes: mediators of bone diseases, protection, and therapeutics potential. Oncoscience. 2018;5:181-95.

3. Carney R, Hazari S, Rojalin T, Knudson A, Gao T, Tang Y, Liu R, Viitala T, Yliperttula M, Lam K. Targeting Tumor-Associated Exosomes with IntegrinBinding Peptides. Adv Biosyst. 2017;1:1600038.

4. Akers JC, Gonda D, Kim R, Carter BS, Chen CC. Biogenesis of extracellular vesicles (EV): exosomes, microvesicles, retrovirus-like vesicles, and apoptotic bodies. J Neuro-Oncol. 2013;113:1-11.

5. Mao L, Li X, Gong S, Yuan H, Jiang Y, Huang W, Sun X, Dang X. Serum exosomes contain ECRG4 mRNA that suppresses tumor growth via inhibition of genes involved in inflammation, cell proliferation, and angiogenesis. Cancer Gene Ther. 2018. https://doi.org/10.1038/s41417-0180032-3.

6. Chaput N, Thery C. Exosomes: immune properties and potential clinical implementations. Semin Immunopathol. 2011:33:419-40.

7. Chiarugi P, Cirri P. Metabolic exchanges within tumor microenvironment. Cancer Lett. 2016:380:272-80.

8. Kahlert C, Kalluri R. Exosomes in tumor microenvironment influence cancer progression and metastasis. Journal of Molecular Medicine-Jmm. 2013:91:431-7.

9. Benmoussa A, Ly S, Shan S, Laugier J, Boilard E, Gilbert C, Provost P. A subset of extracellular vesicles carries the bulk of microRNAs in commercial dairy cow's milk. J Extracell Vesicles. 2017;6:1401897.

10. Tkach $\mathrm{M}$, Thery $\mathrm{C}$. Communication by extracellular vesicles: where we are and where we need to go. Cell. 2016;164:1226-32.

11. Sanz-Rubio D, Martin-Burriel I, Gil A, Cubero P, Forner M, Khalyfa A, Marin JM. Stability of circulating Exosomal miRNAs in healthy subjects. Sci Rep. 2018;8:10

12. Hannafon BN, Ding WQ. Intercellular communication by exosome-derived microRNAs in Cancer. Int J Mol Sci. 2013;14:14240-69.

13. Ramachandran S, Palanisamy V. Horizontal transfer of RNAs: exosomes as mediators of intercellular communication. Wiley Interdisciplinary ReviewsRna. 2012:3:286-93.

14. Lee Y, El Andaloussi S, Wood MJA. Exosomes and microvesicles: extracellular vesicles for genetic information transfer and gene therapy. Hum Mol Genet. 2012;21:R125-34.

15. Tamai K, Tanaka N, Nakano T, Kakazu E, Kondo Y, Inoue J, Shiina M, Fukushima K, Hoshino T, Sano K, et al. Exosome secretion of dendritic cells is regulated by Hrs, an ESCRT-0 protein. Biochem Biophys Res Commun. 2010:399:384-90.

16. Wollert T, Hurley JH. Molecular mechanism of multivesicular body biogenesis by ESCRT complexes. Nature. 2010:464:864-U873.

17. Tran N. Cancer exosomes as miRNA factories. Trends in Cancer. 2016;2:329-31.

18. Qu L, Ding J, Chen C, Wu ZJ, Liu B, Gao Y, Chen W, Liu F, Sun W, Li XF, et al. Exosome-transmitted IncARSR promotes Sunitinib resistance in renal Cancer by acting as a competing endogenous RNA. Cancer Cell. 2016;29:653-68.

19. Schickel R, Boyerinas B, Park SM, Peter ME. MicroRNAs: key players in the immune system, differentiation, tumorigenesis and cell death. Oncogene. 2008;27:5959-74.

20. Zhang J, Li S, Li L, Li M, Guo CY, Yao J, Mi SL. Exosome and Exosomal MicroRNA: trafficking, sorting, and function. Genomics Proteomics \& Bioinformatics. 2015;13:17-24.

21. Ostrowski M, Carmo N, Krumeich S, Fanget I, Raposo G, Savina A, Moita C, Schauer K, Hume A, Freitas R, et al. Rab27a and Rab27b control different steps of the exosome secretion pathway. Nat Cell Biol. 2010;12:19-30 sup pp 11-13.

22. Yu X, Harris S, Levine A. The regulation of exosome secretion: a novel function of the p53 protein. Cancer Res. 2006:66:4795-801.

23. Wang YM, Xu XY, Yu SX, Jeong KJ, Zhou ZC, Han L, Tsang YH, Li J, Chen H, Mangala LS, et al. Systematic characterization of A-to-I RNA editing hotspots in microRNAs across human cancers. Genome Res. 2017;27:1112-25.

24. Baietti M, Zhang Z, Mortier E, Melchior A, Degeest G, Geeraerts A, Ivarsson Y, Depoortere F, Coomans C, Vermeiren E, et al. Syndecan-syntenin-ALIX regulates the biogenesis of exosomes. Nat Cell Biol. 2012;14:677-85.

25. Klemm F, Joyce JA. Microenvironmental regulation of therapeutic response in cancer. Trends Cell Biol. 2015;25:198-213.

26. Challagundla KB, Fanini F, Vannini I, Wise P, Murtadha M, Malinconico L, Cimmino A, Fabbri M. microRNAs in the tumor microenvironment: solving the riddle for a better diagnostics. Expert Rev Mol Diagn. 2014;14:565-74.

27. Lujambio A, Lowe SW. The microcosmos of cancer. Nature. 2012:482:347-55.

28. Wilson WR, Hay MP. Targeting hypoxia in cancer therapy. Nat Rev Cancer. 2011;11:393-410.

29. Taddei ML, Giannoni E, Comito G, Chiarugi P. Microenvironment and tumor cell plasticity: an easy way out. Cancer Lett. 2013;341:80-96.

30. Zhang ZC, Li X, Sun W, Yue SQ, Yang JY, Li JJ, Ma B, Wang JL, Yang XS, Pu M, et al. Loss of exosomal miR-320a from cancer-associated fibroblasts contributes to HCC proliferation and metastasis. Cancer Lett. 2017:397:33-42.

31. Du YE, Tu G, Yang GL, Li GY, Yang D, Lang L, Xi L, Sun KX, Chen YL, Shu KX, et al. MiR-205/YAP1 in activated fibroblasts of breast tumor promotes VEGFindependent angiogenesis through STAT3 signaling. Theranostics. 2017;7: 3972-88.

32. Kohlhapp FJ, Mitra AK, Lengyel E, Peter ME. MicroRNAs as mediators and communicators between cancer cells and the tumor microenvironment. Oncogene. 2015;34:5857-68

33. Pang WJ, Su JJ, Wang YL, Feng H, Dai X, Yuan YZ, Chen X, Yao WY. Pancreatic cancer-secreted miR-155 implicates in the conversion from normal fibroblasts to cancer-associated fibroblasts. Cancer Sci. 2015;106:1362-9.

34. Fang T, Lv H, Lv G, Li T, Wang C, Han Q, Yu L, Su B, Guo L, Huang S, et al. Tumor-derived exosomal miR-1247-3p induces cancer-associated fibroblast activation to foster lung metastasis of liver cancer. Nat Commun. 2018;9:191

35. Greening DW, Gopal SK, Xu R, Simpson RJ, Chen WS. Exosomes and their roles in immune regulation and cancer. Semin Cell Dev Biol. 2015;40:72-81.

36. Que RS, Lin C, Ding GP, Wu ZR, Cao LP. Increasing the immune activity of exosomes: the effect of miRNA-depleted exosome proteins on activating dendritic cell/cytokine-induced killer cells against pancreatic cancer. Journal of Zhejiang University-Science B. 2016;17:352-60.

37. Anastasiadou E, Slack FJ. Malicious exosomes. Science. 2014;346:1459.

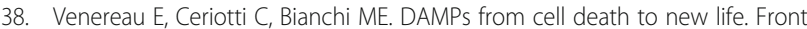
Immunol. 2015;6.

39. Thwe PM, Amiel E. The role of nitric oxide in metabolic regulation of dendritic cell immune function. Cancer Lett. 2018;412:236-42.

40. Hammer GE, Ma A: Molecular control of steady-state dendritic cell maturation and immune homeostasis. IN Annual Review of Immunology, Vol 31. Volume 31. Edited by Littman DR, Yokoyama WM 2013: 743-791: Annual Review of Immunology].

41. Fabbri M, Paone A, Calore F, Galli R, Gaudio E, Santhanam R, Lovat F, Fadda P, Mao C, Nuovo GJ, et al. MicroRNAs bind to toll-like receptors to induce prometastatic inflammatory response. Proc Natl Acad Sci U S A. 2012:109: E2110-6. 
42. Greither T, Grochola LF, Udelnow A, Lautenschlager C, Wurl P, Taubert H. Elevated expression of microRNAs 155, 203, 210 and 222 in pancreatic tumors is associated with poorer survival. Int J Cancer. 2010;126:73-80.

43. Berzins SP, Ritchie DS. Natural killer T cells: drivers or passengers in preventing human disease? Nat Rev Immunol. 2014;14:640-6.

44. Donatelli SS, Zhou JM, Gilvary DL, Eksioglu EA, Chen XH, Cress WD, Haura EB, Schabath MB, Coppola D, Wei S, Djeu JY. TGF-beta-inducible microRNA183 silences tumor-associated natural killer cells. Proc Natl Acad Sci U S A. 2014;111:4203-8.

45. Noman MZ, Buart S, Romero P, Ketari S, Janji B, Mari B, Mami-Chouaib F, Chouaib S. Hypoxia-inducible miR-210 regulates the susceptibility of tumor cells to lysis by cytotoxic T cells. Cancer Res. 2012;72:4629-41.

46. Feitelson MA, Arzumanyan A, Kulathinal RJ, Blain SW, Holcombe RF, Mahajna J, Marino M, Martinez-Chantar ML, Nawroth R, Sanchez-Garcia I, et al. Sustained proliferation in cancer: mechanisms and novel therapeutic targets. Semin Cancer Biol. 2015:35:S25-54.

47. Kogure T, Lin W-L, Yan IK, Braconi C, Patel T. Inter-cellular nanovesicle mediated microRNA transfer: a mechanism of environmental modulation of hepatocellular cancer cell growth. Hepatology (Baltimore, Md). 2011;54: 1237-48.

48. Kim J, Morley S, Le M, Bedoret D, Umetsu DT, Di Vizio D, Freeman MR. Enhanced shedding of extracellular vesicles from amoeboid prostate cancer cells potential effects on the tumor microenvironment. Cancer Biology \& Therapy. 2014;15:409-18.

49. Mo L, Song M, Huang Q, Guan H, Liu X, Xie D, Huang B, Huang R, Zhou P. Exosome-packaged miR-1246 contributes to bystander DNA damage by targeting LIG4. Br J Cancer. 2018;119:492-502.

50. Zhang L, Zhan SY, Yao J, Lowery FJ, Zhang QL, Huang WC, Li P, Li M, Wang $X$, Zhang $C Y$, et al. Microenvironment-induced PTEN loss by exosomal microRNA primes brain metastasis outgrowth. Nature. 2015;527:100-4.

51. Liang XL, Zhang LN, Wang SH, Han Q, Zhao RC. Exosomes secreted by mesenchymal stem cells promote endothelial cell angiogenesis by transferring miR-125a. J Cell Sci. 2016;129:2182-9.

52. Cui H, Seubert B, Stahl E, Dietz H, Reuning U, Moreno-Leon L, Ilie M, Hofman P, Nagase $H$, Mari B, Kruger A. Tissue inhibitor of metalloproteinases-1 induces a pro-tumourigenic increase of miR-210 in lung adenocarcinoma cells and thei exosomes. Oncogene. 2015;34:3640-50.

53. Liu Y, Luo F, Wang BR, Li HQ, Xu Y, Liu XL, Shi L, Lu XL, Xu WC, Lu L, et al. STAT3-regulated exosomal miR-21 promotes angiogenesis and is involved in neoplastic processes of transformed human bronchial epithelial cells. Cancer Lett. 2016;370:125-35.

54. Hood JL, Roman SS, Wickline SA. Exosomes released by melanoma cells prepare sentinel lymph nodes for tumor metastasis. Cancer Res. 2011;71: 3792-801.

55. Gomes FG, Nedel F, Alves AM, Nor JE, Tarquinio SBC. Tumor angiogenesis and lymphangiogenesis: tumor/endothelial crosstalk and cellular/ microenvironmental signaling mechanisms. Life Sci. 2013;92:101-7.

56. Salido-Guadarrama I, Romero-Cordoba S, Peralta-Zaragoza O, HidalgoMiranda A, Rodriguez-Dorantes M. MicroRNAs transported by exosomes in body fluids as mediators of intercellular communication in cancer. Oncotargets and Therapy. 2014;7:1327-38.

57. Yu SR, Cao HX, Shen B, Feng JF. Tumor-derived exosomes in cancer progression and treatment failure. Oncotarget. 2015;6:37151-68.

58. Zhou WY, Fong MY, Min YF, Somlo G, Liu L, Palomares MR, Yu Y, Chow A, O'Connor STF, Chin AR, et al. Cancer-secreted miR-105 destroys vascular endothelial barriers to promote metastasis. Cancer Cell. 2014;25:501-15.

59. Shah MY, Calin GA. The mix of two worlds: non-coding RNAs and hormones. Nucleic Acid Therapeutics. 2013;23:2-8.

60. Uen Y, Wang J, Wang C, Jhang Y, Chung J, Tseng T, Sheu M, Lee S. Mining of potential microRNAs with clinical correlation - regulation of syndecan-1 expression by miR-122-5p altered mobility of breast cancer cells and possible correlation with liver injury. Oncotarget. 2018;9:28165-75.

61. Wang C, Gu S, Cao H, Li Z, Xiang Z, Hu K, Han X. miR-877-3p targets Smad7 and is associated with myofibroblast differentiation and bleomycin-induced lung fibrosis. Sci Rep. 2016;6:30122.

62. Nanbo A, Katano H, Kataoka M, Hoshina S, Sekizuka T, Kuroda M, Ohba Y. Infection of Epstein-Barr virus in type III latency modulates biogenesis of exosomes and the expression profile of Exosomal miRNAs in the Burkitt lymphoma Mutu cell lines. Cancers. 2018;10:237.

63. Konstatinell A, Coucheron D, Sveinbjørnsson B, Moens U. MicroRNAs as Potential Biomarkers in Merkel Cell Carcinoma. Int J Mol Sci. 2018;19:3119-31.
64. Zhao L, Liu WT, Xiao J, Cao BW. The role of exosomes and "exosomal shuttle microRNA" in tumorigenesis and drug resistance. Cancer Lett. 2015; 356:339-46.

65. Takahashi R, Prieto-Vila M, Kohama I, Ochiya T. MicroRNA in body fluids development of the novel plat form for Cancer therapeutics and diagnosis. Gan To Kagaku Ryoho. 2018;45:899-905.

66. Corcoran C, Rani S, O'Brien K, O'Neill A, Prencipe M, Sheikh R, Webb G, McDermott R, Watson W, Crown J, O'Driscoll L. Docetaxel-Resistance in Prostate Cancer: Evaluating Associated Phenotypic Changes and Potential for Resistance Transfer via Exosomes. Plos One. 2012;7:e50999.

67. Corcoran C, Rani S, O'Driscoll L. miR-34a is an intracellular and Exosomal predictive biomarker for response to docetaxel with clinical relevance to prostate Cancer progression. Prostate. 2014;74:1320-34

68. Wei YF, Lai XF, Yu ST, Chen SN, Ma YZ, Zhang Y, Li HC, Zhu XM, Yao LB, Zhang J. Exosomal miR-221/222 enhances tamoxifen resistance in recipient ER-positive breast cancer cells. Breast Cancer Res Treat. 2014;147:423-31.

69. Li B, Ren S, Li X, Wang Y, Garfield D, Zhou S, Chen X, Su C, Chen M, Kuang $P$, et al. MiR-21 overexpression is associated with acquired resistance of EGFR-TKI in non-small cell lung cancer. Lung Cancer. 2014;83:146-53.

70. Ma Y, Xia H, Liu Y, Li M. Silencing miR-21 sensitizes non-small cell lung cancer A549 cells to ionizing radiation through inhibition of PI3K/Akt. Biomed Res Int. 2014;2014:617868.

71. Bica-Pop C, Cojocneanu-Petric R, Magdo L, Raduly L, Gulei D, BerindanNeagoe I. Overview upon miR-21 in lung cancer: focus on NSCLC. Cellular and Molecular Life Sciences. 2018;75:3539-51.

72. Schwarzenbach $\mathrm{H}$. Clinical relevance of circulating, cell-free and Exosomal microRNAs in plasma and serum of breast Cancer patients. Oncology Research and Treatment. 2017:40:423-9.

73. Rotelli MT, Di Lena M, Cavallini A, Lippolis C, Bonfrate L, Chetta N, Portincasa $P$, Altomare DF. Fecal microRNA profile in patients with colorectal carcinoma before and after curative surgery. Int J Color Dis. 2015;30:891-8.

74. Eichelser C, Stückrath I, Müller V, Milde-Langosch K, Wikman H, Pantel K, Schwarzenbach $\mathrm{H}$. Increased serum levels of circulating exosomal microRNA-373 in receptor-negative breast cancer patients. Oncotarget. 2014;5:9650-63.

75. Huang XY, Yuan TZ, Liang MH, Du MJ, Xia S, Dittmar R, Wang D, See W, Costello BA, Quevedo F, et al. Exosomal miR-1290 and miR-375 as prognostic markers in castration-resistant prostate Cancer. Eur Urol. 2015;67:33-41.

76. Matsumura T, Sugimachi K, linuma H, Takahashi Y, Kurashige J, Sawada G, Ueda M, Uchi R, Ueo H, Takano Y, et al. Exosomal microRNA in serum is a novel biomarker of recurrence in human colorectal cancer. Br J Cancer. 2015;113:275-81.

77. Aucher A, Rudnicka D, Davis DM. MicroRNAs transfer from human macrophages to Hepato-carcinoma cells and inhibit proliferation. J Immunol. 2013;191:6250-60.

78. Xu XD, Wu XH, Fan YR, Tan B, Quan Z, Luo CL. Exosome-derived microRNA29 C induces apoptosis of BIU-87 cells by down regulating BCL-2 and MCL-1. Asian Pac J Cancer Prev. 2014;15:3471-6.

79. Lim PK, Bliss SA, Patel SA, Taborga M, Dave MA, Gregory LA, Greco SJ, Bryan M, Patel PS, Rameshwar P. Gap junction-mediated import of MicroRNA from bone marrow stromal cells can elicit cell cycle quiescence in breast Cancer cells. Cancer Res. 2011;71:1550-60.

80. Ge L, Sun X, Hong Q, Li F. Ratiometric NanoCluster Beacon: a label-free and sensitive fluorescent DNA detection platform. ACS Appl Mater Interfaces. 2017;9:13102-10.

81. Xia Y, Wang L, Li J, Chen X, Lan J, Yan A, Lei Y, Yang S, Yang H, Chen J. A Ratiometric fluorescent bioprobe based on carbon dots and Acridone derivate for signal amplification detection Exosomal microRNA. Anal Chem. 2018;90:8969-76.

82. Meads MB, Gatenby RA, Dalton WS. Environment-mediated drug resistance: a major contributor to minimal residual disease. Nat Rev Cancer. 2009;9:665-A674.

83. Syn NL, Wang LZ, Chow EKH, Lim CT, Goh BC. Exosomes in Cancer nanomedicine and immunotherapy: prospects and challenges. Trends Biotechnol. 2017;35:665-76.

84. Barile L, Vassalli G. Exosomes: therapy delivery tools and biomarkers of diseases. Pharmacol Ther. 2017;174:63-78.

85. Shao YK, Shen YW, Chen T, XU F, Chen XW, Zheng S. The functions and clinical applications of tumor-derived exosomes. Oncotarget. 2016;7:60736-51.

86. Yu DD, Wu Y, Shen HY, Lv MM, Chen WX, Zhang XH, Zhong SL, Tang JH, Zhao $\mathrm{JH}$. Exosomes in development, metastasis and drug resistance of breast cancer. Cancer Sci. 2015;106:959-64. 
87. He CJ, Zheng S, Luo Y, Wang B. Exosome Theranostics: biology and translational medicine. Theranostics. 2018;8:237-55.

88. Shimbo K, Miyaki S, Ishitobi H, Kato Y, Kubo T, Shimose S, Ochi M. Exosomeformed synthetic microRNA-143 is transferred to osteosarcoma cells and inhibits their migration. Biochem Biophys Res Commun. 2014;445:381-7.

89. Assmann TS, Recamonde-Mendoza M, de Souza BM, Bauer AC, Crispim D. MicroRNAs and diabetic kidney disease: Systematic review and bioinformatic analysis. Mol Cell Endocrinol. 2018;477:90-102.

90. Chevillet JR, Kang Q, Ruf IK, Briggs HA, Vojtech LN, Hughes SM, Cheng HH, Arroyo JD, Meredith EK, Gallichotte EN, et al. Quantitative and stoichiometric analysis of the microRNA content of exosomes. Proc Natl Acad Sci U S A. 2014;111:14888-93.

91. Jia L, Chopp M, Wang L, Lu X, Szalad A, Zhang Z. Exosomes derived from high-glucose-stimulated Schwann cells promote development of diabetic peripheral neuropathy. FASEB J. 2018:fj201800597R. https://doi.org/10.1096/ fj.201800597R.

92. D'Souza R, Woodhead J, Zeng N, Blenkiron C, Merry T, Cameron-Smith D, Mitchell C. Circulatory exosomal miRNA following intense exercise is unrelated to muscle and plasma miRNA abundances. Am J Physiol Endocrinol Metab. 2018. https://doi.org/10.1152/ajpendo.00138.2018.

93. Moghani-Ghoroghi F, Moshkdanian G, Sehat M, Nematollahi-Mahani SN, Ragerdi-Kashani I, Pasbakhsh P. Melatonin pretreated blastocysts along with calcitonin administration improved implantation by upregulation of heparin binding-epidermal growth factor expression in murine endometrium. Cell J. 2018;19:599-606

94. Moustakas A, Heldin P. TGF beta and matrix-regulated epithelial to mesenchymal transition. Biochimica Et Biophysica Acta-General Subjects. 2014;1840:2621-34.

95. Berchem G, Noman MZ, Bosseler M, Paggetti J, Baconnais S, Le Cam E, Nanbakhsh A, Moussay E, Mami-Chouaib F, Janji B, Chouaib S. Hypoxic tumor-derived microvesicles negatively regulate NK cell function by a mechanism involving TGF- $\beta$ and miR23a transfer. Oncoimmunology. 2016;5: e1062968.

96. Kobayashi M, Salomon C, Tapia J, Illanes S, Mitchell M, Rice G. Ovarian cancer cell invasiveness is associated with discordant exosomal sequestration of Let-7 miRNA and miR-200. J Transl Med. 2014;12:4.

97. Tsukerman P, Stern-Ginossar N, Gur C, Glasner A, Nachmani D, Bauman Y, Yamin R, Vitenshtein A, Stanietsky N, Bar-Mag T, et al. MiR-10b downregulates the stress-induced cell surface molecule MICB, a critical ligand for Cancer cell recognition by natural killer cells. Cancer Res. 2012;72:5463-72.

98. Tang B, Wu W, Wei XW, Li Y, Ren G, Fan WH. Activation of glioma cells generates immune tolerant NKT cells. J Biol Chem. 2014;289:34595-600

99. Yin Y, Cai X, Chen X, Liang HW, Zhang YJ, Li J, Wang ZY, Chen XL, Zhang W, Yokoyama $S$, et al. Tumor-secreted miR-214 induces regulatory T cells: a major link between immune evasion and tumor growth. Cell Res. 2014;24:1164-80.

100. Valencia K, Luis-Ravelo D, Bovy N, Anton I, Martinez-Canarias S, Zandueta C, Ormazabal C, Struman I, Tabruyn S, Rebmann V, et al. miRNA cargo within exosome-like vesicle transfer influences metastatic bone colonization. Mol Oncol. 2014;8:689-703.

101. Rana S, Malinowska K, Zoller M. Exosomal tumor MicroRNA modulates Premetastatic organ cells. Neoplasia. 2013;15:281-+.

102. Liu Q, Yu Z, Yuan S, Xie W, Li C, Hu Z, Xiang Y, Wu N, Wu L, Bai L, Li Y. Circulating exosomal microRNAs as prognostic biomarkers for non-small-cell lung cancer. Oncotarget. 2017;8:13048-58.

103. Grossi I, Salvi A, Baiocchi G, Portolani N, De Petro G. Functional role of microRNA-23b-3p in cancer biology. Microrna. 2018;7:156-166.

104. Chiam K, Wang TT, Watson DI, Mayne GC, Irvine TS, Bright T, Smith L, White IA, Bowen JM, Keefe D, et al. Circulating serum Exosomal miRNAs as potential biomarkers for esophageal adenocarcinoma. J Gastrointest Surg. 2015;19:1208-15.

105. Wang M, Zhao C, Shi H, Zhang B, Zhang L, Zhang X, Wang S, Wu X, Yang T, Huang $F$, et al. Deregulated microRNAs in gastric cancer tissue-derived mesenchymal stem cells: novel biomarkers and a mechanism for gastric cancer. Br J Cancer. 2014;110:1199-210.

106. Dou RX, Nishihara R, Cao Y, Mima THK, Masuda A, Masugi Y, Shi Y, Gu MC, Li WW, da Silva A, et al: MicroRNA let-7, T cells, and patient survival in colorectal Cancer. Cancer Immunology Research 2016, 4:927-935.

107. Lin XJ, Fang JH, Yang XJ, Zhang C, Yuan YF, Zheng LM, Zhuang SM. Hepatocellular carcinoma cell-secreted Exosomal MicroRNA-210 promotes angiogenesis in vitro and in vivo. Molecular Therapy-Nucleic Acids. 2018;11: 243-52.
108. Zhou X, Lu Z, Wang T, Huang Z, Zhu W, Miao Y. Plasma miRNAs in diagnosis and prognosis of pancreatic cancer: a miRNA expression analysis. Gene. 2018;673:181-93.

109. Chen D, Wu X, Xia M, Wu F, Ding J, Jiao Y, Zhan Q, An F. Upregulated exosomic miR-23b-3p plays regulatory roles in the progression of pancreatic cancer. Oncol Rep. 2017;38:2182-8.

110. Bryant R, Pawlowski T, Catto J, Marsden G, Vessella R, Rhees B, Kuslich C, Visakorpi T, Hamdy F. Changes in circulating microRNA levels associated with prostate cancer. Br J Cancer. 2012;106:768-74.

111. Vlaeminck-Guillem V. Extracellular vesicles in prostate Cancer carcinogenesis, diagnosis, and management. Front Oncol. 2018;8:222.

112. Bryzgunova O, Zaripov M, Skvortsova T, Lekchnov E, Grigor'eva A, Zaporozhchenko I, Morozkin E, Ryabchikova E, Yurchenko Y, Voitsitskiy V, Laktionov P. Comparative study of extracellular vesicles from the urine of healthy individuals and prostate Cancer patients. PLoS One. 2016;11: e0157566.

113. Koppers-Lalic D, Hackenberg M, de Menezes R, Misovic B, Wachalska M, Geldof A, Zini N, de Reijke T, Wurdinger T, Vis A, et al. Non-invasive prostate cancer detection by measuring miRNA variants (isomiRs) in urine extracellular vesicles. Oncotarget. 2016;7:22566-78.

114. Ayub S, Kaul D, Ayub T. Microdissecting the role of microRNAs in the pathogenesis of prostate cancer. Cancer Genet. 2015;208:289-302.

115. Li Z, Ma Y, Wang J, Zeng X, Li R, Kang W, Hao X. Exosomal microRNA-141 is upregulated in the serum of prostate cancer patients. Onco Targets Ther. 2016;9:139-48.

116. Xu Y, Qin S, An T, Tang Y, Huang Y, Zheng L. MiR-145 detection in urinary extracellular vesicles increase diagnostic efficiency of prostate cancer based on hydrostatic filtration dialysis method. Prostate. 2017;77:1167-75.

117. Rodríguez M, Bajo-Santos C, Hessvik N, Lorenz S, Fromm B, Berge V, Sandvig $\mathrm{K}$, Linē A, Llorente A. Identification of non-invasive miRNAs biomarkers for prostate cancer by deep sequencing analysis of urinary exosomes. Mol Cancer. 2017;16:156.

118. Wani S, Kaul D, Mavuduru R, Kakkar N, Bhatia A. Urinary-exosomal miR-2909: a novel pathognomonic trait of prostate cancer severity. J Biotechnol. 2017; 259:135-9.

119. Endzelinš E, Berger A, Melne V, Bajo-Santos C, Sobolevska K, Ābols A, Rodriguez M, Šantare D, Rudnickiha A, Lietuvietis V, et al. Detection of circulating miRNAs: comparative analysis of extracellular vesicleincorporated miRNAs and cell-free miRNAs in whole plasma of prostate cancer patients. BMC Cancer. 2017:17:730.

120. Bhagirath D, Yang T, Bucay N, Sekhon K, Majid S, Shahryari V, Dahiya R, Tanaka Y, Saini S. microRNA-1246 is an Exosomal biomarker for aggressive prostate Cancer. Cancer Res. 2018;78:1833-44.

121. Wang WW, Zhong $W$, Yuan $J H$, Yan CC, Hu SP, Tong YP, Mao YB, Hu TH, Zhang B, Song G. Involvement of Wnt/beta-catenin signaling in the mesenchymal stem cells promote metastatic growth and chemoresistance of cholangiocarcinoma. Oncotarget. 2015;6:42276-89.

122. Singh R, Pochampally R, Watabe K, Lu Z, Mo Y. Exosome-mediated transfer of miR-10b promotes cell invasion in breast cancer. Mol Cancer. 2014;13:256.

123. Kosaka N, lguchi H, Hagiwara K, Yoshioka Y, Takeshita F, Ochiya T. Neutral sphingomyelinase 2 (nSMase2)-dependent Exosomal transfer of Angiogenic MicroRNAs regulate Cancer cell metastasis. J Biol Chem. 2013;288:10849-59.

124. Wen Y, Chen R, Zhu CH, Qiao HM, Liu Y, Ji H, Miao JY, Chen LY, Liu XX, Yang Y. MiR-503 suppresses hypoxia-induced proliferation, migration and angiogenesis of endothelial progenitor cells by targeting Apelin. Peptides. 2018;105:58-65

125. Vannini I, Fanini F, Fabbri M. Emerging roles of microRNAs in cancer. Curr Opin Genet Dev. 2018;48:128-33.

126. Tadokoro H, Umezu T, Ohyashiki K, Hirano T, Ohyashiki JH. Exosomes derived from hypoxic leukemia cells enhance tube formation in endothelial cells. J Biol Chem. 2013;288:34343-51.

127. Gernapudi R, Yao Y, Zhang YS, Wolfson B, Roy S, Duru N, Eades G, Yang PX, Zhou Q. Targeting exosomes from preadipocytes inhibits preadipocyte to cancer stem cell signaling in early-stage breast cancer. Breast Cancer Res Treat. 2015;150:685-95.

128. Fong MY, Zhou WY, Liu L, Alontaga AY, Chandra M, Ashby J, Chow A O'Connor STF, Li SS, Chin AR, et al. Breast-cancer-secreted miR-122 reprograms glucose metabolism in premetastatic niche to promote metastasis. Nat Cell Biol. 2015;17:183-+. 
129. Ung T, Madsen H, Hellwinkel J, Lencioni A, Graner M. Exosome proteomics reveals transcriptional regulator proteins with potential to mediate downstream pathways. Cancer Sci. 2014;105:1384-1392.

130. Chen KK, Chen Y, Chen Z, Shi YY, He ZM, Ding BH, Wang CL, Yu L. miR-134 increases the antitumor effects of cytarabine by targeting Mnks in acute myeloid leukemia cells. Oncotargets and Therapy. 2018;11:3141-7.

131. Yang M, Chen J, Su F, Yu B, Su F, Lin L, Liu Y, Huang J, Song E. Microvesicles secreted by macrophages shuttle invasion-potentiating microRNAs into breast cancer cells. Mol Cancer. 2011;10:117.

132. Lee HK, Finniss S, Cazacu S, Bucris E, Ziv-Av A, Xiang CL, Bobbitt K, Rempel SA, Hasselbach L, Mikkelsen T, et al. Mesenchymal stem cells deliver synthetic microRNA mimics to glioma cells and glioma stem cells and inhibit their cell migration and self-renewal. Oncotarget. 2013;4:346-61.

133. Baglio SR, Rooijers K, Koppers-Lalic D, Verweij FJ, Lanzon MP, Zini N, Naaijkens B, Perut F, Niessen HWM, Baldini N, Pegtel DM. Human bone marrow- and adipose-mesenchymal stem cells secrete exosomes enriched in distinctive miRNA and tRNA species. Stem Cell Res Ther. 2015;6.

134. Le M, Hamar P, Guo C, Basar E, Perdigão-Henriques R, Balaj L, Lieberman J. miR-200-containing extracellular vesicles promote breast cancer cell metastasis. J Clin Invest. 2014;124:5109-128.

135. Cheng L, Wu S, Zhang K, Qing Y, Xu T. A comprehensive overview of exosomes in ovarian cancer: emerging biomarkers and therapeutic strategies. J Ovarian Res. 2017;10:73.

136. Yi H, Ye J, Yang XM, Zhang LW, Zhang ZG, Chen YP. High-grade ovarian cancer secreting effective exosomes in tumor angiogenesis. Int J Clin Exp Pathol. 2015;8:5062-70

137. Ye SB, Li ZL, Luo DH, Huang BJ, Chen YS, Zhang XS, Cui J, Zeng YX, Li J. Tumor-derived exosomes promote tumor progression and T-cell dysfunction through the regulation of enriched exosomal microRNAs in human nasopharyngeal carcinoma. Oncotarget. 2014;5:5439-52.

138. Bi L, Yang Q, Yuan J, Miao Q, Duan L, Li F, Wang S. MicroRNA-127-3p acts as a tumor suppressor in epithelial ovarian cancer by regulating the BAG5 gene. Oncol Rep. 2016;36:2563-70.

139. Dessauge F, Cayla X, Albar J, Fleischer A, Ghadiri A, Duhamel M, Rebollo A. Identification of PP1alpha as a caspase-9 regulator in IL-2 deprivationinduced apoptosis. J Immunol. 2006;177:2441-51.

140. Zhang S, Zhang X, Fu X, Li W, Xing S, Yang Y. Identification of common differentially-expressed miRNAs in ovarian cancer cells and their exosomes compared with normal ovarian surface epithelial cell cells. Oncol Lett. 2018; 16:2391-401.

141. Nishiyama M, Skoultchi A, Nakayama K. Histone $\mathrm{H} 1$ recruitment by CHD8 is essential for suppression of the Wnt- $\beta$-catenin signaling pathway. Mol Cell Biol. 2012;32:501-12.

142. Deng Y, Deng H, Liu J, Han G, Malkoski S, Liu B, Zhao R, Wang X, Zhang Q. Transcriptional down-regulation of Brca1 and E-cadherin by CtBP1 in breast cancer. Mol Carcinog. 2012;51:500-7.

143. Challagundla K, Wise P, Neviani P, Chava H, Murtadha M, Xu T, Kennedy R, Ivan C, Zhang X, Vannini I, et al. Exosome-mediated transfer of microRNAs within the tumor microenvironment and neuroblastoma resistance to chemotherapy. J Natl Cancer Inst. 2015;107:djv135.

144. Cerutti C, Edwards LJ, de Vries HE, Sharrack B, Male DK, Romero IA. MiR-126 and miR-126*regulate shear-resistant firm leukocyte adhesion to human brain endothelium. Sci Rep. 2017;7:45284

145. Farahani M, Rubbi C, Liu L, Slupsky JR, Kalakonda N. CLL Exosomes Modulate the Transcriptome and Behaviour of Recipient Stromal Cells and Are Selectively Enriched in miR-202-3p. Plos One. 2015;10:e0141429.

146. Umezu T, Ohyashiki K, Kuroda M, Ohyashiki JH. Leukemia cell to endothelial cell communication via exosomal miRNAs. Oncogene. 2013; 32:2747-55.

147. Paggetti J, Haderk F, Seiffert M, Janji B, Distler U, Ammerlaan W, Kim YJ, Adam J, Lichter P, Solary E, et al. Exosomes released by chronic lymphocytic leukemia cells induce the transition of stromal cells into cancer-associated fibroblasts. Blood. 2015;126:1106-17.

148. Umezu T, Tadokoro H, Azuma K, Yoshizawa S, Ohyashiki K, Ohyashiki JH. Exosomal miR-135b shed from hypoxic multiple myeloma cells enhances angiogenesis by targeting factor-inhibiting HIF-1. Blood. 2014;124:3748-57.

149. Isola AL, Eddy K, Chen S. Biology, Therapy and Implications of Tumor Exosomes in the Progression of Melanoma. Cancers. 2016;8:110.

150. Eisenstein A, Gonzalez EC, Raghunathan R, Xu XX, Wu MZ, McLean EO, McGee J, Ryu B, Alani RM. Emerging biomarkers in cutaneous melanoma. Molecular Diagnosis \& Therapy. 2018;22:203-18.
151. Felicetti F, De Feo A, Coscia C, Puglisi R, Pedini F, Pasquini L, Bellenghi M, Errico MC, Pagani E, Care A. Exosome-mediated transfer of miR-222 is sufficient to increase tumor malignancy in melanoma. J Transl Med. 2016;14:56.

152. Veija T, Sahi H, Koljonen V, Bohling T, Knuutila S, Mosakhani N. miRNA-34a underexpressed in Merkel cell polyomavirus-negative Merkel cell carcinoma. Virchows Arch. 2015:466:289-95.

\section{Ready to submit your research? Choose BMC and benefit from:}

- fast, convenient online submission

- thorough peer review by experienced researchers in your field

- rapid publication on acceptance

- support for research data, including large and complex data types

- gold Open Access which fosters wider collaboration and increased citations

- maximum visibility for your research: over $100 \mathrm{M}$ website views per year

At BMC, research is always in progress.

Learn more biomedcentral.com/submissions 